\title{
A Density Scale Based on Solid Objects
}

\author{
Horace A. Bowman, Randall M. Schoonover, and C. Leon Carroll \\ Institute for Basic Standards, National Bureau of Standards, Washington, D.C. 20234
}

(October 15, 1973)

\begin{abstract}
We have determined the density of four pieces of single crystal silicon in terms of universally accepted standards of mass and length. These four objects will be used as a working density standard to which all future density work in the United States will be referred. Using these crystals as standards, NBS can calibrate other objects as density standards for associated laboratories.

The work was accomplished with the assistance of an interferometer, developed especially for the task, which measures the diameter of commercially available steel balls. From measured diameters ball volumes are calculated. The volumetric information contained in the balls is transferred to the silicon crystals in a newly designed hydrostatic weighing experiment.

We have made three independent density determinations on each of the four crystals, and the presently accepted values of the density of each crystal is the average of the three determinations. The random component of uncertainty ( 3 standard deviations) of these four averages is $0.7 \mathrm{ppm}$. The systematic error is estimated to be about $0.7 \mathrm{ppm}$.
\end{abstract}

Key words: Density standard; hydrostatic weighing; perfect sphere; silicon; spherical interferometer; spherical volume; volume standard.

\section{Contents}

Page

1.2. Modern developments .......................

1.3. Dissemination of density information...... 15

2. The working standard of density .............. 15

2.1. Material for density standards ............ $\quad 15$

2.2. Sizes of crystals............................ 16

2.3. Mass measurements..................... 16

2.4. Verification of volumes ...................... 16

2.4.1. Objects of perfect geometry ............ 16

2.4.2. Diametric measurements .............. 16

2.4.2.1. The interferometer configuration .............................

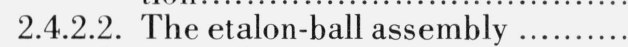

2.4.2.3. Interferometer temperature measurements....................

2.4.2.4. Etalon length measurements......

2.4.2.5. Ball diameter measurements .....

\section{6}

17

17

20

20
2.4.2.6. The temperature coefficients of linear expansion of the balls......

2.5 Hydrostatic transfer of volumetric information from the spheres to the crystals...

2.5.1. The hydrostatic system.................

2.5.1.1. The hydrostatic suspension .........

2.5.1.2. The hydrostatic liquid ..............

2.5.1.3. The immersed pan loading assembly - redundancy ..............

2.5.1.4. The hydrostatic balance and its calibration.

2.5.2. Hydrostatic weighing on a directreading balance .......................

2.5.3. Hydrostatic weighing format - the 4-1 ratio series

2.6. Final calculation of crystal volumes and

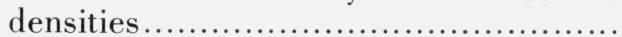

3. References
Page

\section{Introduction}

In the early 1960's NBS began receiving inquiries as to the practicability of making density measurements to an uncertainty of a part or two in a million. This was of particular interest to oceanographers and crystalographers. Cook, NPL, $[1,2],{ }^{1}$ had satisfied the requirements of workers in gas thermodynamics by

${ }^{1}$ Figures in brackets indicate the literature references at the end of this paper. his determination of the density of mercury to about a part in a million and he had made a generous supply available to NBS. We made several efforts to transfer the density information from this mercury into various objects but this is a difficult experiment and we were rarely able to achieve reproducibility of independent measurements to less than three parts per million. We had some immediate "in house" requirements for density knowledge to a part per million in the field 
of fundamental constants $[3,4]$ and, as a long range objective, an improvement of the mass standard.

In 1965 we announced [5] that NBS would undertake to devise a density measurement procedure and the necessary associated standards tied directly to the universally recognized standards of mass and length so that interested experimenters could make such density determinations. We had already demonstrated that the densities of solid objects could be compared to a precision of $1: 10^{7}$ or better [6] so we stated that the proposed measurement system would be based upon a group of solid objects, and we outlined the procedures we would use in the development. Numerous experimental failures have required us to alter our techniques and methods, but every experiment has reinforced our original conclusion that solid density standards are far more practical than any liquid standard which has come to our attention.

Section 2 of this paper outlines the laboratory procedures we used in the development of the system and the results we obtained.

\subsection{Background}

All density determinations require two measurements, one to find the mass of the unknown and a second to find its volume. Mass may be adequately measured by well understood procedures. Volume may be calculated from linear measurements, but it is ordinarily calculated from observed data on buoyant forces in hydrostatic weighing tests in water of some tabulated value of density.

Cook's determination on mercury was in response to a well-defined problem of very widespread interest, and NPL expended a great deal of effort in accomplishing this excellent measurement to about a part in a million.

The suggestion has frequently been made that if NBS would determine the density of well characterized water from a reproducible source, that other groups could use this type of water, after preparation by a welldefined recipe, for $1 \mathrm{ppm}$ density measurements. Nothing could be further from the truth. While such a determination by NBS might remove some of the uncertainty associated with the use of water as a density standard, no prudent experimenter would claim such accuracy because such a claim would necessarily have to be based upon four assumptions-none of which are subject to proof:

1. That the published value of the density of water applied without correction to the particular sample used in his measurement.

2. That the official recipe for preparation of water contained no hidden errors when applied to his particular sample.

3. That no blunders were made during preparation of his sample.

4. That no contamination occurred between the preparation and use of his sample.

There are two additional practical reasons for choosing a solid-based density scale in preference to water: (1) It is possible to compare the densities of two solids to a precision in excess of that which is achievable in the comparison of a solid with water. (2) The density of an unknown liquid may be determined much more easily from a solid standard than from water.

\subsection{Modern Developments}

There have been numerous technical developments in the past two decades which greatly facilitate the task of developing a solid-based density scale. We utilized five of these developments:

a. The inexpensive commercial availability of single-crystal silicon.

b. The commercial availability at reasonable cost of steel spheres of near-perfect geometry.

c. A new type interferometer designed by J. B. Saunders, NBS [8].

d. The commercial availability of Lamb dip stabilized lasers and techniques for their ready calibration with reference to universally recognized spectral standards [7]. This made the above interferometer configuration practical.

e. A completely redesigned hydrostatic weighing experiment.

Due to the enormous requirements of the electronics industry, single crystal silicon is now mass-produced in sizes much greater than necessary for practical density standards. The virtues of this remarkable material as density standards will be discussed in section 2 , but its primary value in such service is its homogeneity and density stability.

A major difficulty facing a laboratory about to embark on a fundamental density measurement is the fabrication of an object of such geometric perfection that its volume may be calculated from linear measurements.

We avoided facing this problem directly by using commercially available steel balls about $6.3 \mathrm{~cm}$ in diameter. The difference between the maximum diameters and the minimum diameters of such spheres is rarely greater than about $1 \mathrm{ppm}$.

The virtues of spherical objects have long been recognized, but there has been no practical method of measuring spherical diameters without introducing uncertainties (such as contact deformation) several times the magnitude of the desirable level of uncertainty. This problem was resolved by the development of the noncontacting interferometer mentioned above.

Volumes calculated from such measured diameters are not indefinitely stable because steel balls are easily damaged by scratches, corrosion, rough handling, etc., so it was desirable to transfer the volumetric knowledge irom the spheres to objects of better stability and homogeneity in density. This transfer is performed hydrostatically.

The classical hydrostatic weighing experiment is quite imprecise and most wasteful of density knowl- 
edge. In order to get the precision of this operation below $1 \mathrm{ppm}$ we made four changes:

1. The use of a fluorocarbon instead of water.

2. The use of four comparison objects instead of one.

3. The use of direct reading, damped balances instead of free swinging instruments.

4. The employment of a measurement procedure designed for the determination of volumetric ratios rather than densities.

The foregoing remarks suggest the apparatus and procedures we used in developing our working density standard. The work described in this report, outlined in figure 1, was largely exploratory, and we have found that equipment and procedural modifications will provide data of equal or better quality at much less cost in the future.

\section{The Working Standard of Density}

Inasmuch as density is defined in terms of mass and length, both of which are basic in the SI System, it would be inappropriate to speak of a density standard in the context in which the word "standard" is generally understood. On the other hand, "working" standards are ordinarily thought of as convenience items whose accepted values are obtained by calibration either directly or indirectly against fundamental standards.

For this reason, we have chosen to refer to our group of silicon crystals as a "working" standard. The accepted density values of the individual crystals in this group are not invariantly fixed, but only represent our best estimate of the true value based upon previous calibration experience. As additional measurement

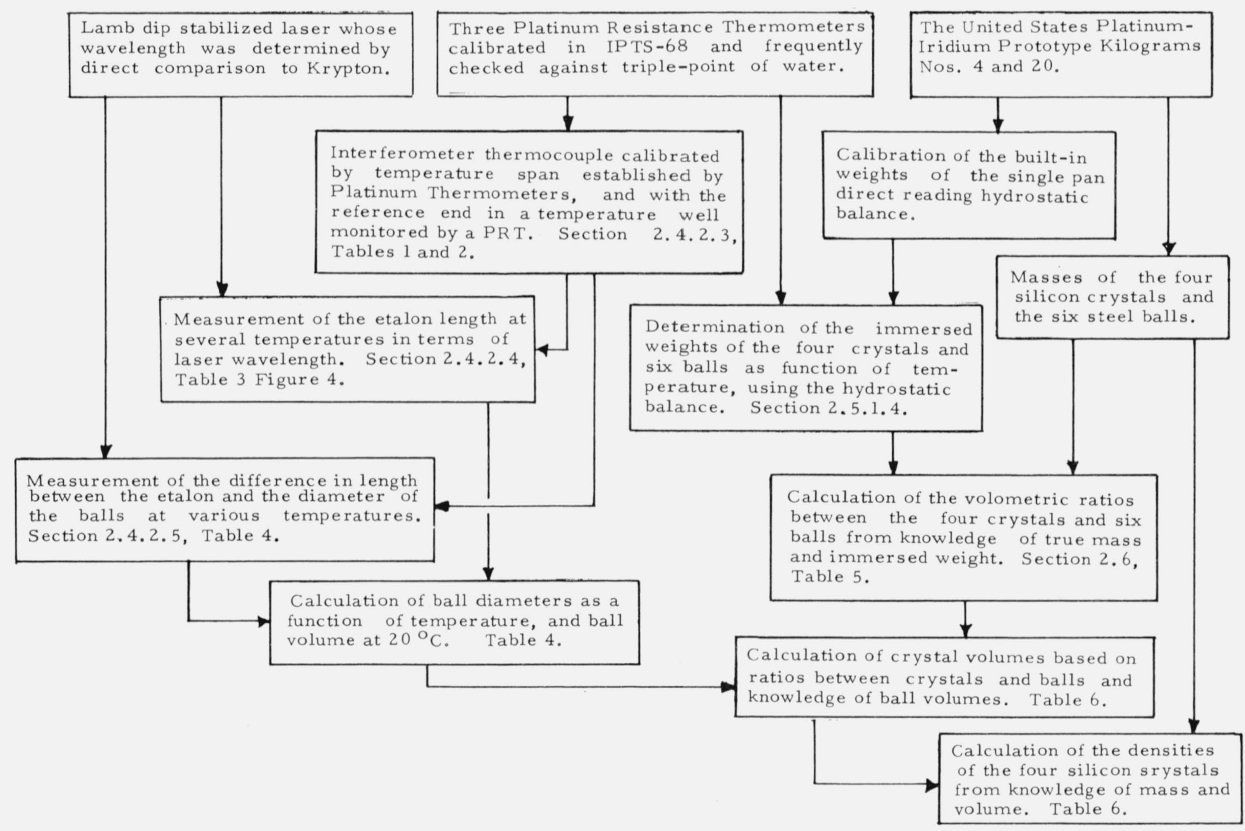

FigURE 1

Additional work on these crystals and balls will be performed as a continuing NBS project, and will be reported on from time to time.

\subsection{Dissemination of Densizy Information}

By hydrostatic transfer from our crystals or balls, we are now in a position to calibrate solid standards for use by other laboratories.

If other groups choose to enter the field of fundamental volumetric (density) measurements (we have heard of two such organizations), it will be possible to exchange solid density standards to assure consistency.

The use of solid standards makes comparison of density scales to assure consistency a practical procedure. effort is expended, the accepted values may be slightly modified. The present accepted values of our crystals are based upon the average of three independent determinations.

\subsection{Material for Density Standards}

The most important characteristics of an artifact standard of a physical property are:

1. Temporal stability with respect to the physical property it represents.

2. Adaptability to practical measurement methods.

3 . Of such a nature that the response of a measurement system is primarily due to the characteristic of interest. 
Single crystal silicon meets all of the above requirements to a far greater degree than any of the other materials we considered. It is among the most homogeneous materials available so that chipping or abrasion in use cause equal percentages of loss of mass and volume (density constant). It has a highly stable surface in that the oxide film is formed in a minute or so-thereafter changes occur at a rate estimated to be such that the gross density of the crystal varies by about (worst case) $1 / 10 \mathrm{ppm} /$ year [9]. Its oxide has a density very nearly equal to that of the parent material. It has sufficient electrical conductivity so that, with care, electrostatic charges do not interfere with weighing. Its temperature coefficient of expansion is only 2.5 $\mathrm{ppm} /{ }^{\circ} \mathrm{C}$ (linear). It is inert in most liquids. It is easily fabricated into desirable shapes and sizes. There are many commercial sources of supply at moderate cost. Inexpensive lightly doped transistor grades are quite adequate in this application. The pieces of silicon used in our working standard were cut from a reject boule given to us by the Fairchild Semiconductor Company.

\subsection{Sizes of Crystals}

Our working density standard is made up of four silicon crystals cut from a $2 \frac{1}{2}$-in diam boule in slices about 1 -in thick. They were ground down to about $205 \mathrm{~g}$ each and then trimmed to about $200 \mathrm{~g}$ by HF etching which exposed the parent crystal lattice surface with work damage removed.

\subsection{Mass Measurements}

Our measurements required knowledge of the mass of three groups of objects:

1. The steel balls

2. The silicon crystals

3. The built-in weights from our direct-reading balance.

The mass of the balls and crystals were determined in conventional " $4-1$ " weighing series ${ }^{2}$ commencing with our national standard of mass to which BIPM had assigned a value. The balance weights were removed from the balance and were worked down from the national standard in weighing series especially designed for the purpose. Uncertainty in the mass of the balls was about $64 \mu$-grams, in the crystals about $45 \mu$-grams, and about $12 \mu$-grams per hundred grams for the balance weights.

\subsection{Verification of Volumes}

\subsubsection{Objects of Perfect Geometry}

While it would have been possible within the present day state-of-the-art to fabricate our crystals into perfect geometric forms and calculate their

2 Designs involving measurements of the $n(n-1) / 2$ distinct differences among $n$ objects are referred to in this paper as " $n-1$ " designs. volumes from linear measurements, this would have been prohibitively costly. As pointed out in the introduction, we intend to continue our program of mass and volume measurements on our crystals for an indefinite period. Under these circumstances, if a crystal became chipped, its geometric perfection would be destroyed and volumetric surveillance would necessarily have to stop. The fabrication of any geometrically perfect object is a major undertaking-it was a real problem for NPL during their mercury work, BIPM during their work on water and for Hart and Morgan [10] on silicon.

We were fortunate to discover that nearly perfect spheres of 52100 steel [11] were available from at least two companies supplying the needs of groups working in inertial navigation. These spheres were $6.35 \mathrm{~cm}$ in diameter. Our spherical profile instruments could not detect lobing down to about $1 \mathrm{ppm}$ of diameter. Daniel P. Johnson, NBS, has demonstrated (see companion paper in this issue at NBS J. Res.) that the true volumes of such spheres differ insignificantly from the volumes calculated on the basis of the true average diameter. We attempt to obtain a close approximation to this true average diameter by making "many" diametric measurements.

We initially obtained four balls, A, B, C, and D. When the experiment was in progress it became evident that six balls were desirable. Rather than delay the experiment while awaiting two additional balls we used balls $A$ and $B$ a second time in another density determination. In this second determination in which balls $\mathrm{A}$ and $\mathrm{B}$ were employed, we have referred to them as balls $\mathrm{E}$ and $\mathrm{F}$.

Hereafter, in this report, we will refer to six balls, $\mathrm{A}, \mathrm{B}, \mathrm{C}, \mathrm{D}, \mathrm{E}$, and $\mathrm{F}$, although, in fact, there are only four. This is justified in section 2.6.

\subsubsection{Diametric Measurements}

The conventional method of measuring spherical diameters is by comparison with stacks of gage blocks in mechanical contacting devices. This involves deformation errors which are directly additive with gage block and ringing film errors. A most careful search of the literature did not disclose a convenient noncontacting interferometer configuration for this task.

Our interferometer specialist, J. B. Saunders, was persuaded to delay his retirement until he had developed such an instrument. In less than 1 year he presented us with a laboratory device. This configuration is given in detail elsewhere [8], but it will be briefly described below.

\subsubsection{The Interferometer Configuration}

This instrument is an etalon device whose major components are laid out as illustrated in figure 2 . Laser light enters face 1 of a conventional beam-splitter prism where it is split into two beams, $\mathrm{L}$ and $\mathrm{R}$, leaving the prism through faces 2 and 3 respectively. These two beams are directed by mirrors into the opposite 


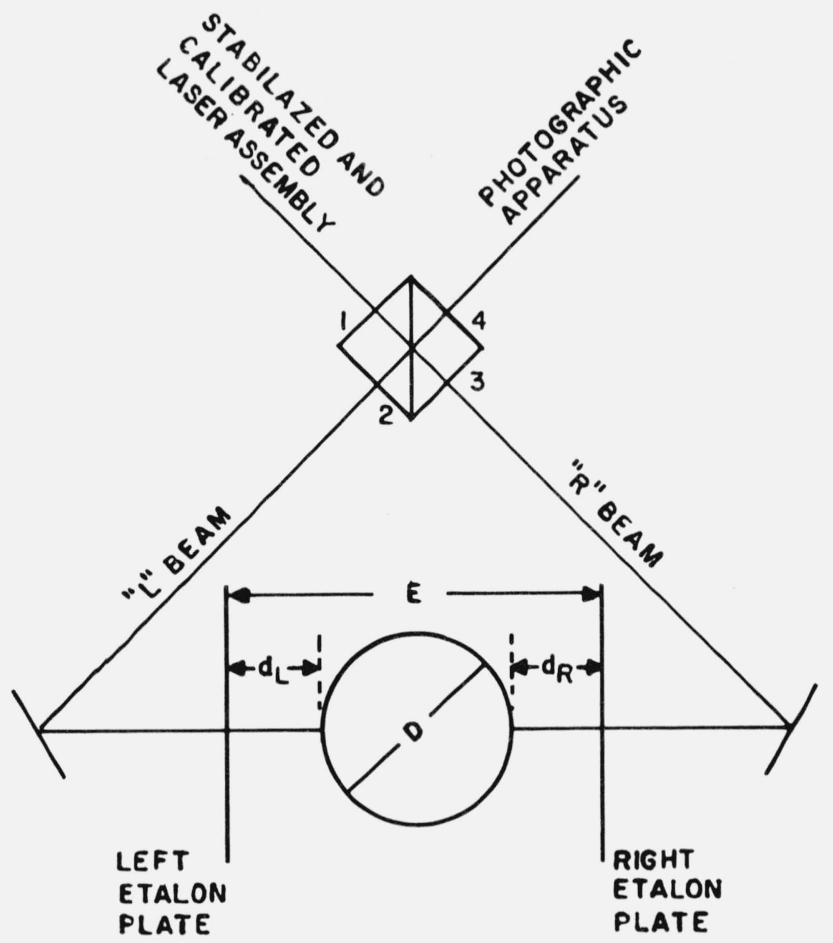

FigURE 2. A schmetic diagram of principal members of the Saunders ball and cylinder interferometer

ends of an etalon, the $\mathrm{L}$ beam striking the left etalon plate normally and the $\mathrm{R}$ beam striking the right plate. A ball is placed in the etalon and oriented so that the two beams are directed toward the center of the ball. The $\mathrm{L}$ beam and the $\mathrm{R}$ beam are used one at a time, the undesired beam being masked off by a screen near the prism. With the $\mathrm{R}$ beam masked, the $\mathrm{L}$ beam strikes the left etalon face which reflects part of the light back toward the prism. The balance of light passes through the left etalon plate and strikes the spherical ball surface, which reflects it back toward the prism. These two reflected beams interfere with one another in a bull's-eye pattern (since one beam is divergent) which is photographed by a camera placed opposite face 4 of the prism. When this photo has been taken, the operator masks off the $\mathrm{L}$ beam and photographs the pattern caused by interference between $R$ beam light reflected from the right etalon plate and the right side of the ball. This is a fast operation using $1 / 15$ second exposures on $35 \mathrm{~mm}$ film. For high contrast interferograms, the two interfering beams should be of about equal intensity. With one reflected beam coming from a quartz surface and the other from a highly polished steel surface, this requirement is not met. Saunders overcame this difficulty by backing the camera away from the prism. The (approximately collimated) beam of low intensity reflected from the quartz etalon plate was about constant in intensity regardless of the camera position, however, the (divergent) beam of high intensity reflected from the highly polished steel spherical surface became attenuated (due to divergence) as the distance between the prism and camera increased. The photographs were made with the film placed in the plane of equal intensity, so the interferograms were of extremely high contrast. The two interferograms are associated with distances $d_{\mathrm{L}}$ and $d_{\mathrm{R}}$ on the sketch. It is obvious that if $\mathrm{E}$ is the etalon length, the ball diameter, $D$, is given by

$$
\begin{gathered}
D=E-d_{\mathrm{L}}-d_{\mathrm{R}} . \\
\text { 2.4.2.2. The Etalon-Ball Assembly }
\end{gathered}
$$

The etalon consists of two quartz flats about $1-\mathrm{cm}$ thick separated by an internal distance of $68 \mathrm{~mm}$ (millimeters). The spheres are a maximum of about 63 $\mathrm{mm}$ in diameter so they are easily inserted and removed from the etalon. The two flats are held rigidly by two quartz plates, above and below, by epoxy cement. Each plate has a $7-\mathrm{cm}$ hole through the center. The hole through the upper plate allows various balls to be inserted in the etalon, and the rotating ball holder comes up from below through the hole in the lower plate.

The ball rests on three rollers arranged so that it may be rotated about two axes $90^{\circ}$ apart by remote controls. This makes it possible to measure the diameter through any set of latitudes and longitudes on the ball surface. In practice we made measurements on 10 diameters (20 photos) normal to the faces of an inscribed duodecahedron, and gave each measured diameter equal weight in the calculation of the average.

$$
\text { 2.4.2.3. Interferometer Temperature Measurements }
$$

Due to the small size of the temperature coefficients involved, temperature measurements of adequate accuracy are easily attainable during etalon measurement tests. Two such coefficients are of importancethe temperature coefficient of wavelength, $+1 \mathrm{ppm} /{ }^{\circ} \mathrm{C}$, and the temperature coefficient of expansion of the etalon, about $+.5 \mathrm{ppm} /{ }^{\circ} \mathrm{C}$. Since these coefficients have the same algebraic sign, they are opposed in their effect on the etalon measurement, adding to about $-0.5 \mathrm{ppm} /{ }^{\circ} \mathrm{C}$ to the effective etalon length.

On the other hand, the temperature coefficient of expansion of the 52100 steel balls is in excess of 12 $\mathrm{ppm} /{ }^{\circ} \mathrm{C}$ (which amounts to $36 \mathrm{ppm} /{ }^{\circ} \mathrm{C}$ in volume), so that ball temperatures must be measured to the best possible accuracy.

The etalon assembly, described in the previous section, is housed in a double wall chamber with thermostat water circulating in the walls, base, and cover. There are four thermal leaks in this isothermal shield. We have 2 windows about $2 \mathrm{~cm}$ in diameter in the walls to permit entrance of the two measuring light beams. The ball rotation control column enters through a $5-\mathrm{cm}$ diameter hole in the floor, and the measuring thermocouple penetrates the shield through a $2-\mathrm{cm}$ diameter hole in the cover. We initially hoped that the thermostat shield would be strong enough to define the temperatures of the steel ball and etalon to a level less than $0.01{ }^{\circ} \mathrm{C}$ so that a temperature measurement on the thermostat liquid would satisfy all requirements. However, in developmental 
experiments, we found that the difference between the ball temperature and the thermostat water varied randomly over a range of about $\pm 0.02{ }^{\circ} \mathrm{C}$ at periods of 1 to 3 minutes.

This required that we measure the ball temperature directly. We constructed a measuring thermocouple in the form of a copper-constantan thermopile with six pairs of junctions. The six reference junctions were soaked in a temperature well which was monitored by a platinum resistance thermometer. Each of the six measuring junctions entered the interferometer chamber through the hole in the top and were held in physical contact with the steel ball by the springiness of the wire leads. Each measuring junction was covered by a thin layer of epoxy to prevent their electrical short-circuiting through the ball. Both the lightness of the physical contact between the ball and the measuring junctions and the epoxy coating mitigated against good thermal contact between them.

The indication of a potentiometer-thermocouple combination is a function of the difference in temperature between the junctions of the thermocouple. To make meaningful measurements one must make every effort to assure that the thermal contact between the measuring junction and the object of interest is such that the temperature of the junction is equal to the temperature of the object of interest. Failing this, an evaluation must be made of the difference in temperature if such difference exists.
To calibrate a temperature measuring system of this type requires two experiments:

1. A determination of the relationship between the potentiometer output and the difference between the temperatures of the opposite thermocouple junctions.

2. A determination of the difference in temperature between the measuring junctions of the thermocouple and that of the object of interest as a function of whatever perturbing influence causes this difference to depart from zero.

The data from the first experiment, table 1, showed that the potentiometer output (in nominal millivolts) was a linear function of the difference in temperature between the opposite junctions. A line of the form

$$
\begin{aligned}
\Delta T & =\alpha(\mathrm{emf})+\beta \text { was fitted to the data to obtain } \\
\alpha & \left.=4.12069^{\circ} \mathrm{C} / \mathrm{mv} \text { (std. dev. }=0.00589\right) \\
\beta & \left.=0.000585^{\circ} \mathrm{C} \text { (std. dev. }=0.00149\right) .
\end{aligned}
$$

During this experiment, the reference junction was kept in the temperature well employed during the ball diameter tests, and the measuring junctions were deeply immersed in a liquid bath. Platinum resistance thermometers monitored each temperature, and triple

\begin{tabular}{|c|c|c|c|c|c|c|c|}
\hline Date-t & & $\begin{array}{c}\text { Temperature } \\
\text { of } \\
\text { bath }\end{array}$ & $\begin{array}{l}\text { Temperature } \\
\text { of } \\
\text { reference well }\end{array}$ & & $\Delta T$ & $\begin{array}{l}\text { Poter } \\
\text { obse }\end{array}$ & $\begin{array}{l}\text { ometer } \\
\text { vation } \\
\text { nf }\end{array}$ \\
\hline $12-15-72$ & 0845 & 20.053 & 19.944 & & 0.109 & & 0.026 \\
\hline & 1230 & 20.012 & 19.947 & & .065 & & .016 \\
\hline $12-18-72$ & 0840 & 19.806 & 19.949 & $(-)$ & .143 & $(-)$ & .036 \\
\hline & 1630 & 20.082 & 19.819 & & .263 & & .066 \\
\hline $12-19-72$ & 0835 & 20.090 & 19.672 & & .418 & & .102 \\
\hline & 0930 & 20.089 & 19.670 & & .419 & & .103 \\
\hline & 1105 & 20.096 & 19.668 & & .428 & & .104 \\
\hline & 1520 & 20.093 & 19.674 & & .419 & & .101 \\
\hline $12-20-72$ & 0830 & 19.467 & 19.713 & $(-)$ & .246 & $(-)$ & .061 \\
\hline & 0910 & 19.460 & 19.714 & $(-)$ & .254 & $(-)$ & .0625 \\
\hline & 1100 & 21.366 & 19.720 & & 1.646 & & .398 \\
\hline & 1335 & 21.366 & 19.734 & & 1.632 & & .396 \\
\hline & 1530 & 21.899 & 19.742 & & 2.157 & & .523 \\
\hline $12-21-72$ & 0855 & 21.824 & 19.756 & & 2.068 & & .502 \\
\hline
\end{tabular}
point of water measurements by these two ther-

TABLE 1

This data was taken with good thermal contact between the calibrating ambients and the two ends of the thermocouple. The reference end was in the temperature well used during measurements, and the working junctions were in a thermostat bath. Both the bath and well were monitored by platinum resistance thermometers. Triple-point of water measurement histories on the two thermometers indicate that maximum errors in observed values of $\Delta T$ are no greater than $0.0014{ }^{\circ} \mathrm{C}$.

This data fits a straight line of the form

where

$$
\begin{aligned}
\Delta T & =\alpha(\mathrm{EMF})+\beta \\
\alpha & =4.120693 \quad(\text { standard deviation }=0.00589) \\
\beta & =0.000585048 \quad(\text { standard deviation }=0.00149) .
\end{aligned}
$$


mometers indicated that the temperature span in the thermocouple calibration experiment was defined to no worse than $0.001{ }^{\circ} \mathrm{C}$.

Having obtained a good measure of the potentiometer output as a function of the difference between junction temperatures, we turned our attention to obtaining a measure of the difference between the true ball temperature and the temperature of the measuring junction of the thermocouple. This second experiment was performed on a ball and thermocouple nominally identical to those used in the ball diameter measuring tests. In this experiment the reference junctions of the thermocouple were cemented to the ball surface with several centimeters of lead wire held against this surface by insulating tape-the intent was to insure that the reference junction was in excellent thermal contact with the ball so that the junction temperature was equal to the ball temperature. The thermocouple wires were led away from the reference junction and passed through the interferometer wall (into the room) through one of the windows in the side of the thermostat chamber. The measuring junctions of this thermocouple were reinserted into the interferometer through the opening in the top cover and held in light contact with the ball by the springiness of the lead wires in exactly the same manner as the measuring junctions of the thermocouple used in ball diameter tests. Assuming that there were negligible thermal gradients in the steel ball and that the reference junction was in adequate thermal contact with the ball surface, we concluded that the output of this thermocouple indicated the difference between the true temperature of the ball and that of the measuring junction.

The test showed that the temperature of the measuring junction was higher than the ball temperature when the room temperature was higher and vice versa. The data, table 2 and figure 3 , were fitted to the equation

$Z=A_{2} q^{2}+A_{1} q+A_{0}$

where

$A_{2}=8.718 \times 10^{-4}$

$A_{1}=1.652 \times 10^{-2}$

$A_{0}=3.038 \times 19^{-3}$

$q=$ The difference in temperature between the room temperature and the ball temperature

$Z=$ the difference in temperature between the ball and the measuring junction.
TABLE 2

\begin{tabular}{lc|c|c|c}
\hline \hline \multicolumn{2}{c|}{ Date-time } & $\begin{array}{c}\Delta T \text { indicated } \\
\text { by } \\
\text { thermocouple }\end{array}$ & $\begin{array}{c}\text { Room } \\
\text { temperature }\end{array}$ & $\begin{array}{c}\text { Thermostat } \\
\text { temperature }\end{array}$ \\
\hline $11-2-72$ & 0845 & $-0.025^{\circ} \mathrm{C}$ & $19.50^{\circ} \mathrm{C}$ & 21.00 \\
$11-3-72$ & 1155 & +.022 & 19.50 & 18.40 \\
$11-6-72$ & 0820 & +.009 & 19.49 & 19.39 \\
$11-7-72$ & 1320 & -.025 & 19.40 & 21.40 \\
$11-8-72$ & 1315 & -.044 & 19.50 & 22.81 \\
$11-9-72$ & 1621 & .000 & 19.50 & 19.63 \\
$11-10-72$ & 1100 & +.025 & 20.71 & 19.68 \\
$11-13-72$ & 1500 & +.028 & 20.73 & 19.40 \\
$11-14-72$ & 0836 & +.019 & 20.80 & 19.70 \\
$11-15-72$ & 0834 & -.019 & 20.80 & 22.10 \\
$11-16-72$ & 0814 & -.016 & 20.8 & 22.1 \\
$11-17-72$ & 1534 & +.047 & 20.8 & 18.41 \\
$11-20-72$ & 0840 & -.031 & 20.88 & 23.25 \\
$11-21-72$ & & +.050 & 20.77 & 18.21 \\
$11-24-72$ & 1200 & -.031 & 20.8 & 23.25 \\
$11-27-72$ & 0900 & -.044 & 19.4 & 23.1 \\
\hline
\end{tabular}

This data was taken with the reference junctions of the thermocouple held in good thermal contact with a dummy steel ball by epoxy cement. The measuring junctions were in only moderate thermal contact (simulating that which existed during the ball diameter tests).

This data fits a curve of the form

$$
Z=A_{2} q^{2}+A_{1} q+A_{0}
$$

where

$$
\begin{aligned}
& A_{0}=3.038263 \times 10^{-3} \\
& A_{1}=1.652534 \times 10^{-2} \\
& A_{2}=8.718282+10^{-4} \\
& Z=\text { Error in thermocouple indication due to } \\
& q=\text { (presumably) lead losses. } \\
& q=\text { (Room Temp) }- \text { (Thermostat Temp). }
\end{aligned}
$$

During this experiment we used the temperature of the water in the interferometer walls as the criterion for judging true ball temperature. It was previously pointed out that this was false to the extent of about $\pm 0.02{ }^{\circ} \mathrm{C}$ but an error of this magnitude has negligible effect on the coefficients shown above.

We feel quite certain that the major perturbation on the ball temperature indicated by the thermocouple was heat flow in the thermocouple leads, but we do not understand why there is a slight quadratic bend in our data, nor why our data does not pass through zero $\left(A_{0}=0\right)$. We believe that heat flow in the ball rotation control column may cause nonlinear data. Failure of the data to pass through the origin may indicate some perturbing influence we have not found.

Ball temperatures reported during the interferometric tests on their diameters were calculated as follows:

1. The temperature span of the thermocouple was calculated from $\Delta T=4.12069(\mathrm{emf})+0.000585$.

2. The value of $\Delta T$, calculated thus, was algebraically added to the PRT indication of the temperature inside of the temperature well. This provided us with the temperature of the measuring junction.

3 . The difference between the room temperature and the temperature of the measuring junction 


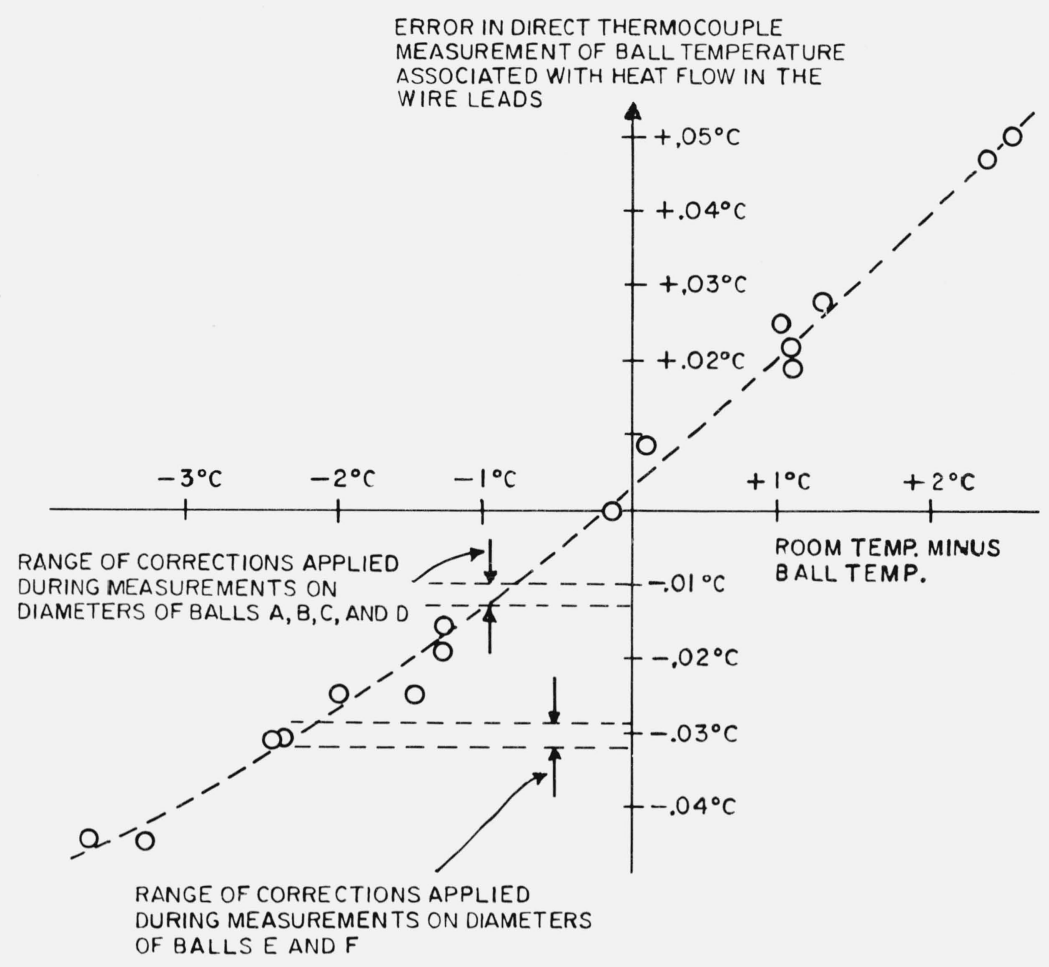

FIGURE 3. This is a plot of data taken during measurements on the errors in temperature observations caused by heat flow in the thermocouple leads.

was taken to be an adequate indication of $q$ (above), and the temperature of the measuring junction was corrected by the factor

$8.718 \times 10^{-4} \times q^{2}+1.652 \times 10^{-2} \times q+3.038 \times 10^{-3}$

We believe that the reported ball temperatures are uncertain by no more than $0.009^{\circ} \mathrm{C}$.

\subsubsection{Etalon Length Measurements}

The detailed procedure for measuring the length of the etalon is given in Saunder's paper. It consists of modifying the basic configuration of the instrument so that interference occurs between beams of light reflected from the two etalon surfaces. One beam results from an internal reflection so that its phase is shifted by $180^{\circ}$. Our fringe fractions are calculated from measurements on rings of constructive interference and we assume that the phase shift in the shifted beam is a retardation. Under this assumption, the length of the etalon is given by

$$
E=\frac{\lambda N_{E}-0.316}{2}
$$

where $E$ is the etalon length, $N_{E}$ the total fringe count, integral plus fractional, and $\lambda$ the wavelength of the laser light. The -0.316 in the numerator is the $180^{\circ}$ phase shift correction mentioned above $(\lambda=0.6328 \mu)$.
Our Lamb dip stabilized laser has been calibrated three times as follows:

$\begin{array}{rr}1970 & 0.632991408 \mu \mathrm{m} \\ 1971 & .632991409 \mu \mathrm{m} \\ 1972 & .632991411 \mu \mathrm{m}\end{array}$

Our measurements were made between the second two calibrations, and we assume that the vacuum wavelength was $0.632991410 \mu$ during ball measurements.

We made six measurements on our etalon length at six different temperatures. The data is shown in table 3 and figure 4. It was found to fit a straight line of slope $0.036259 \mu /{ }^{\circ} \mathrm{C}$. From these tests we calculate the temperature coefficient of linear expansion to be 0.000000537 , with a standard deviation of 0.000000016 . The NBS group specializing in this work estimated the coefficient of the quartz to be 0.000000540 (士.000 00003$)$.

$$
\text { 2.4.2.5. Ball Diameter Measurements }
$$

As previously mentioned, the ball diameter, $D$, is given by $D=E-d_{\mathrm{L}}-d_{\mathrm{R}}$, figure 2 . The measurement of $E$ was discussed in the previous section. We are concerned here with the measurements of $d_{\mathrm{L}}$ and $d_{\mathrm{R}}$. It is well known that the phase of light reflected from a steel surface is retarded with respect to light reflected from an equidistant quartz surface. This retardation has most recently been measured by 
TABLE 3

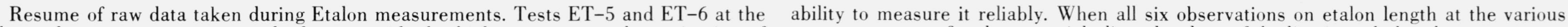
elevated temperature were made for use with the high temperature determination of ball diameters and volumetric ratios in Determination $\mathrm{E}-\mathrm{F}$. Fringes were photographed with the interfering light beams travelling in both directions through the interferometer.

emperatures are fitted to a straight line the slope of the line is such that the temperature with the inteffere

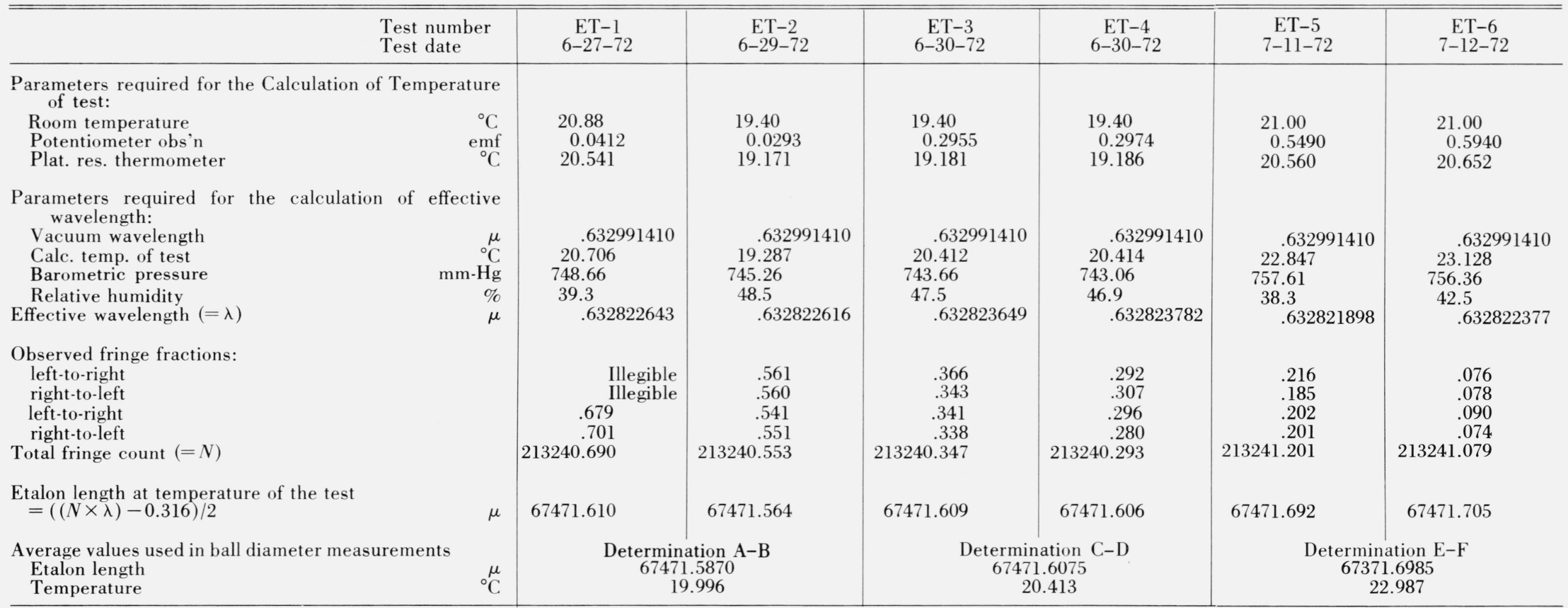




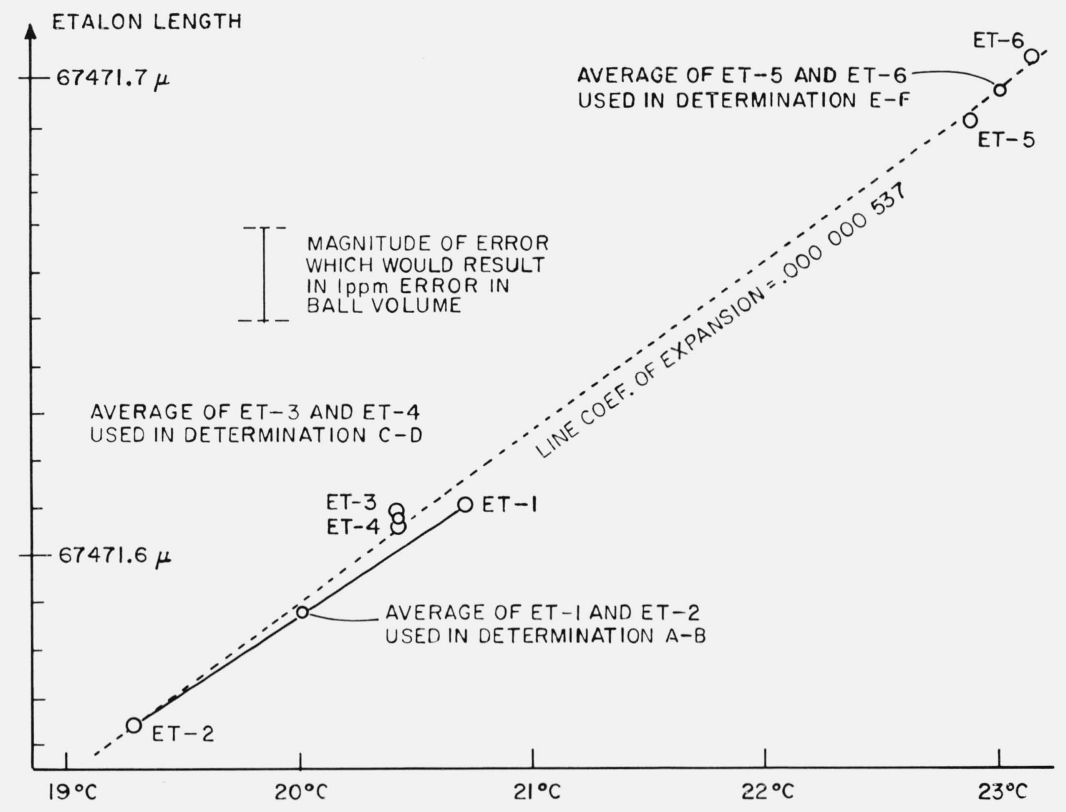

FIGURE 4. This is a plot of the measurements made on the etalon at various temperatures.

Raw data are presented in table 3 from the data presented here the temperature coefficient of linear expansion is indicated to be 0.000000537 .

Bennet [12] and we have used her value of $22^{\circ}$ in our calculations. Inasmuch as we assume the $180^{\circ}$ phase shift from a quartz reflector to be a retardation, we must for consistency assume the phase shift from a steel surface to be $202^{\circ}\left(180^{\circ}+22^{\circ}\right)$ retardation. This is $0.355 \mu \mathrm{m}$ in the case of light whose wavelength is $0.6328 \mu \mathrm{m}$.

As pointed out previously we make two interference photographs, one associated with $d_{L}$, the other with $d_{R}$. Then

$$
\begin{aligned}
& d_{L}=\frac{\left(n_{1}+L\right) \lambda-0.355}{2} \\
& d_{R}=\frac{\left(n_{2}+R\right) \lambda-0.355}{2}
\end{aligned}
$$

where $n_{1}$ and $n_{2}$ are the integral orders in the two interferograms and $L$ and $R$ the fractional orders. Adding the above two equations and letting $n_{1}+n_{2}=N_{B}$ we get

$$
d_{L}+d_{R}=\frac{\left(N_{B}+L+R\right) \lambda-0.710}{2}
$$

We have made four diametric measurements on each of our six balls. Each measurement is the average of 10 diameters (pairs of interferograms) taken uniformly over the spherical surface. The data are shown in table 4 . The values of $L, R$ and $L+R$ are shown. The sum, $d_{L}+d_{R}$, is the mechanical path difference (M.P.D.) and average values at average temperatures are shown in the caption. The temperatures in the four measurements are averaged as are the four final calculated diameters for use in calculating coef. of expansion and the average values are shown in the caption. These four diameters at various temperatures are reduced to values at $20^{\circ} \mathrm{C}$ to provide a criterion for estimating the interferometric precision. The justification for the value of the temperature coefficient of linear expansion used in this reduction is given in the following section.

From the average diameter at $20{ }^{\circ} \mathrm{C}$ the volume of the ball at $20{ }^{\circ} \mathrm{C}$ is calculated. These two average values are also given in the caption to table 4 .

2.4.2.6. The Temperature Coefficients of Linear Expansion of the Balls

In its present form our ball interferometer must be readjusted whenever its temperature is changed more than a few tenths of a degree. For this reason, it is not practical to insert a ball and vary the temperature to get data for a temperature-diameter slope. We have tried this, and the calculated slopes are unrealistically high.

Our interferometer experiment provides us with a value of M.P.D., that is, the difference between the length of the etalon and the diameter of the ball at the temperature of the test. An acceptable estimate of the coefficient can be obtained by dividing the diameter-temperature slope $(\Delta$ dia $/ \Delta$ temp) by the average diameter of the ball over this range, 6.3501 $\mathrm{cm}$. The slope may be calculated from the relationship

$$
\frac{\left(\text { MPD@ } t_{1}\right)-\left(\text { MPD @ } t_{2}\right)+(\text { expansion of etalon })}{t_{2}-t_{1}}
$$


TABLE 4a. Resume of raw data taken during interferometric tests on Ball $A$

\author{
Average test temperature $=20.2375^{\circ} \mathrm{C}$ \\ Averaged measured diameter $=63500.2966 \mu$ \\ Averaged measured MPD $=3971.2991 \mu$
}

Data reduction is based upon an assumed etalon length of 67471.5870 microns at $19.996{ }^{\circ} \mathrm{C}$ based upon the average values obtained in Etalon tests ET-1 and ET-2. The
temperature coefficient of linear expansion of the etalon is assumed to be 0.000000537

and of the steel ball, 0.000012272 . The values of the diameter of the ball at $20^{\circ} \mathrm{C}$ repro-

duce in the four tests to a standard deviation of the mean of 0.0070 microns. Average Values at $20^{\circ} \mathrm{C}$ : Dia $6.35001116 \mathrm{~cm}$; Vol. $134.067062 \mathrm{~cm}^{3}$

\begin{tabular}{|c|c|c|c|c|c|c|c|c|c|c|c|c|c|}
\hline & & \multicolumn{12}{|c|}{ Date of test } \\
\hline & & \multicolumn{3}{|c|}{$2-17-72$} & \multicolumn{3}{|c|}{$2-28-72$} & \multicolumn{3}{|c|}{$3-3-72$} & \multicolumn{3}{|c|}{$3-6-72$} \\
\hline $\begin{array}{l}\text { Potentiometer Indication of thermocouple output (milli- } \\
\text { volts nominal) }\end{array}$ & $\begin{array}{r}\text { lst } \\
2 \mathrm{nd} \\
3 \mathrm{rd} \\
4 \mathrm{th} \\
5 \text { th }\end{array}$ & : & & $\begin{array}{l}\text { Avg. } \\
.2628\end{array}$ & $\begin{array}{l}.288 \\
.288 \\
.288 \\
.288 \\
.287\end{array}$ & & $\begin{array}{l}\text { Avg. } \\
.2878\end{array}$ & $\begin{array}{l}.286 \\
.287 \\
.286 \\
.286 \\
.285\end{array}$ & & $\begin{array}{l}\text { Avg. } \\
.2860\end{array}$ & $\begin{array}{l}.292 \\
.292 \\
.292 \\
.291 \\
.291\end{array}$ & & $\begin{array}{l}\text { Avg. } \\
.2916\end{array}$ \\
\hline $\begin{array}{l}\text { Room temperature } \\
\text { Thermocouple span } \\
\text { Reference temperature well-PRT } \\
\text { Correction for lead losses } \\
\text { Temperature of ball diameter test } \\
\text { Barometric pressure } \\
\text { Relative humidity } \\
\text { Effective wavelength }(\lambda)\end{array}$ & $\begin{array}{r}{ }^{\circ} \mathrm{C} \\
{ }^{\circ} \mathrm{C} \\
{ }^{\circ} \mathrm{C} \\
{ }^{\circ} \mathrm{C} \\
{ }^{\circ} \mathrm{C} \\
{ }^{\circ} \mathrm{C} \\
\mathrm{mm} \cdot \mathrm{Hg} \\
\mu\end{array}$ & \multicolumn{3}{|c|}{$\begin{array}{c}19.32 \\
1.084 \\
19.182 \\
.012 \\
20.278 \\
748.66 \\
21.4 \\
.6328 \quad 22277\end{array}$} & \multicolumn{3}{|c|}{$\begin{array}{c}19.25 \\
1.187 \\
19.017 \\
.012 \\
20.216 \\
750.01 \\
25.2 \\
6328 \quad 21958\end{array}$} & \multicolumn{3}{|c|}{$\begin{array}{l}19.30 \\
1.179 \\
19.048 \\
.011 \\
20.238 \\
742.19 \\
33.3 \\
6328 \quad 23789\end{array}$} & \multicolumn{3}{|c|}{$\begin{array}{c}19.40 \\
1.202 \\
19.006 \\
.010 \\
20.218 \\
755.86 \\
14.7 \\
.6328 \quad 20572\end{array}$} \\
\hline $\mathrm{R}=$ Right fraction $\quad \mathrm{L}=$ Left fraction & & $\mathrm{L}$ & $\mathrm{R}$ & $\mathrm{L}+\mathrm{R}$ & $\mathrm{L}$ & $\mathrm{R}$ & $\mathrm{L}+\mathrm{R}$ & $\mathrm{L}$ & $\mathrm{R}$ & $\mathrm{L}+\mathrm{R}$ & $\mathrm{L}$ & $\mathrm{R}$ & $\mathrm{L}+\mathrm{R}$ \\
\hline \multirow[t]{2}{*}{$\begin{array}{l}\text { Fringe fractions calculated from measurements made on } \\
\text { interferometer negatives (constructive interference) }\end{array}$} & $\begin{array}{c}\text { lst } \\
2 \text { nd } \\
\text { 3rd } \\
4 \text { th } \\
5 \text { th } \\
6 \text { th } \\
7 \text { th } \\
8 \text { th } \\
9 \text { th } \\
10 \text { th }\end{array}$ & $\begin{array}{l}.872 \\
.514 \\
.893 \\
.528 \\
.694 \\
.425 \\
.414 \\
.855 \\
.395 \\
.672\end{array}$ & $\begin{array}{l}.238 \\
.639 \\
.156 \\
.563 \\
.453 \\
.668 \\
.700 \\
.307 \\
.738 \\
.436\end{array}$ & $\begin{array}{l}.110 \\
.153 \\
.049 \\
.091 \\
.147 \\
.093 \\
.114 \\
.162 \\
.133 \\
.108\end{array}$ & $\begin{array}{l}.370 \\
.649 \\
.632 \\
.769 \\
.477 \\
.046 \\
.286 \\
.445 \\
.\end{array}$ & $\begin{array}{l}.984 \\
.634 \\
.631 \\
.564 \\
.841 \\
.276 \\
.014 \\
.823 \\
. \\
.\end{array}$ & $\begin{array}{l}.354 \\
.283 \\
.263 \\
.333 \\
.318 \\
.322 \\
.300 \\
.268 \\
. \\
.\end{array}$ & $\begin{array}{l}.795 \\
.293 \\
.491 \\
.313 \\
.192 \\
.103 \\
.176 \\
.681 \\
.211 \\
.351\end{array}$ & $\begin{array}{l}.422 \\
.783 \\
.535 \\
.803 \\
.054 \\
.068 \\
.888 \\
.411 \\
.894 \\
.707\end{array}$ & $\begin{array}{l}.217 \\
.076 \\
.026 \\
.116 \\
.246 \\
.171 \\
.064 \\
.092 \\
.105 \\
.058\end{array}$ & $\begin{array}{l}.364 \\
.192 \\
.923 \\
.197 \\
.868 \\
.972 \\
.144 \\
.036 \\
.915 \\
.163\end{array}$ & $\begin{array}{l}.921 \\
.038 \\
.194 \\
.053 \\
.363 \\
.360 \\
.110 \\
.148 \\
.318 \\
.219\end{array}$ & $\begin{array}{l}.285 \\
.230 \\
.117 \\
.250 \\
.231 \\
.332 \\
.254 \\
.184 \\
.233 \\
.382\end{array}$ \\
\hline & Average & & & .116 & & & .305 & & & .117 & & & .250 \\
\hline $\begin{array}{l}\text { Total fringe count }(N) \\
((N \times \lambda)-0.710) / 2=\text { MPD } \\
\text { Etalon length at test temperature } \\
\text { Ball diameter at test temperature } \\
\text { Ball diameter at } 20^{\circ} \mathrm{C}\end{array}$ & $\begin{array}{l}\mu \\
\mu \\
\mu \\
\mu\end{array}$ & \multicolumn{3}{|c|}{$\begin{array}{l}12552.116 \\
3971.2743 \\
67471.5972 \\
63500.3229 \\
63500.1063\end{array}$} & \multicolumn{3}{|c|}{$\begin{array}{l}12552.305 \\
3971.3321 \\
67471.5950 \\
63500.2629 \\
63500.0946\end{array}$} & \multicolumn{3}{|c|}{$\begin{array}{c}12552.117 \\
3971.2841 \\
67471.5957 \\
63500.3116 \\
63500.1262\end{array}$} & \multicolumn{3}{|c|}{$\begin{array}{l}12552.250 \\
3971.3060 \\
67471.5950 \\
63500.2890 \\
63500.1191\end{array}$} \\
\hline
\end{tabular}


TABLE $4 \mathrm{~b} . \quad$ Resume of raw data taken during interferometric tests on Ball B

$$
\begin{aligned}
& \text { Average test temperature }=20.2275{ }^{\circ} \mathrm{C} \\
& \text { Averaged measured diameter }=63500.2614 \mu \\
& \text { Averaged Measured MPD }=3971.3340 \mu
\end{aligned}
$$

Data reduction is based upon an assumed etalon length of 67471.5870 microns at $19.996{ }^{\circ} \mathrm{C}$ based upon the average values obtained in Etalon tests ET- 1 and ET -2 . The temperature coefficient of linear expansion of the etalon is assumed to be 0.000000537

and of the steel ball, 0.000012272 . The values of the diameter of the ball at $20^{\circ} \mathrm{C}$ reproduce in the four tests to a standard deviation of the mean of 0.0040 microns. Average

\begin{tabular}{|c|c|c|c|c|c|c|c|c|c|c|c|c|c|}
\hline & & \multicolumn{12}{|c|}{ Date of test } \\
\hline & & \multicolumn{3}{|c|}{$2-18-72$} & \multicolumn{3}{|c|}{$2-29-72$} & \multicolumn{3}{|c|}{$3-7-72$} & \multicolumn{3}{|c|}{$3-8-72$} \\
\hline $\begin{array}{l}\text { Potentiometer indication of thermocouple output (milli- } \\
\text { volts nominal) }\end{array}$ & $\begin{array}{l}\text { 1st } \\
\text { 2nd } \\
3 \mathrm{rd} \\
4 \text { th } \\
5 \text { th }\end{array}$ & & & $\begin{array}{l}\text { Avg. } \\
.2526\end{array}$ & $\begin{array}{l}.274 \\
.274 \\
.273 \\
.274 \\
.\end{array}$ & & $\begin{array}{l}\text { Avg. } \\
.2737\end{array}$ & $\begin{array}{l}.293 \\
.293 \\
.294 \\
.293 \\
.\end{array}$ & & $\begin{array}{l}\text { Avg. } \\
.2932\end{array}$ & $\begin{array}{l}.290 \\
.291 \\
.290 \\
.289\end{array}$ & & $\begin{array}{l}\text { Avg. } \\
.2900\end{array}$ \\
\hline $\begin{array}{l}\text { Room temperature } \\
\text { Thermocouple span } \\
\text { Reference temperature well - PRT } \\
\text { Correction for lead losses } \\
\text { Temperature of ball diameter test } \\
\text { Barometric pressure } \\
\text { Relative humidity } \\
\text { Effective wavelength }(\lambda)\end{array}$ & $\begin{array}{r}{ }^{\circ} \mathrm{C} \\
{ }^{\circ} \mathrm{C} \\
{ }^{\circ} \mathrm{C} \\
{ }^{\circ} \mathrm{C} \\
{ }^{\circ} \mathrm{C} \\
\mathrm{mm} \cdot \mathrm{Hg} \\
\% \\
\mu\end{array}$ & \multicolumn{3}{|c|}{$\begin{array}{c}19.30 \\
1.042 \\
19.194 \\
.012 \\
20.248 \\
749.56 \\
25.5 \\
.6328 \quad 22081\end{array}$} & \multicolumn{3}{|c|}{$\begin{array}{c}19.30 \\
1.128 \\
19.095 \\
.011 \\
20.234 \\
748.46 \\
30.2 \\
.6328 \quad 22350\end{array}$} & \multicolumn{3}{|c|}{$\begin{array}{c}19.30 \\
1.209 \\
18.995 \\
.011 \\
20.215 \\
751.74 \\
20.1 \\
.6328 \quad 21535\end{array}$} & \multicolumn{3}{|c|}{$\begin{array}{c}19.30 \\
1.196 \\
19.006 \\
.011 \\
20.213 \\
747.09 \\
24.5 \\
.6328 \quad 22612\end{array}$} \\
\hline $\mathrm{R}=$ Right fraction $\quad \mathrm{L}=$ Left fraction & & $\mathrm{L}$ & $\mathrm{R}$ & $L+R$ & $\mathrm{~L}$ & $\mathrm{R}$ & $L+R$ & $\mathrm{~L}$ & $\mathrm{R}$ & $\mathrm{L}+\mathrm{R}$ & $\mathrm{L}$ & $\mathrm{R}$ & $L+R$ \\
\hline \multirow[t]{2}{*}{$\begin{array}{l}\text { Fringe fractions calculated from Measurements made on } \\
\text { interferometer negatives (constructive interference) }\end{array}$} & $\begin{array}{r}\text { 1st } \\
2 \text { nd } \\
\text { 3rd } \\
4 \text { th } \\
5 \text { th } \\
6 \text { th } \\
7 \text { th } \\
8 \text { th } \\
9 \text { th } \\
10 \text { th }\end{array}$ & $\begin{array}{l}.711 \\
.047 \\
.443 \\
.113 \\
.353 \\
.034 \\
.112 \\
.798 \\
.975 \\
.946\end{array}$ & $\begin{array}{l}.705 \\
.254 \\
.808 \\
.136 \\
.852 \\
.251 \\
.123 \\
.517 \\
.297 \\
.282\end{array}$ & $\begin{array}{l}.416 \\
.301 \\
.251 \\
.249 \\
.205 \\
.285 \\
.235 \\
.315 \\
.272 \\
.228\end{array}$ & $\begin{array}{l}.157 \\
.628 \\
.934 \\
.679 \\
.043 \\
.658 \\
.264 \\
.470 \\
.439 \\
.916\end{array}$ & $\begin{array}{l}.186 \\
.563 \\
.316 \\
.624 \\
.237 \\
.682 \\
.995 \\
.778 \\
.793 \\
.459\end{array}$ & $\begin{array}{l}.343 \\
.191 \\
.250 \\
.303 \\
.280 \\
.340 \\
.259 \\
.248 \\
.232 \\
.375\end{array}$ & $\begin{array}{l}.216 \\
.676 \\
.128 \\
.342 \\
.468 \\
.060 \\
.058 \\
.293 \\
.267 \\
.362\end{array}$ & $\begin{array}{l}.174 \\
.697 \\
.039 \\
.940 \\
.861 \\
.201 \\
.281 \\
.091 \\
.054 \\
.948\end{array}$ & $\begin{array}{l}.390 \\
.373 \\
.167 \\
.282 \\
.329 \\
.261 \\
.339 \\
.384 \\
.321 \\
.310\end{array}$ & $\begin{array}{l}.645 \\
.361 \\
.500 \\
.495 \\
.902 \\
.199 \\
.557 \\
.622 \\
.532 \\
.525\end{array}$ & $\begin{array}{l}.780 \\
.031 \\
.803 \\
.782 \\
.428 \\
.132 \\
.905 \\
.826 \\
.717 \\
.810\end{array}$ & $\begin{array}{l}.425 \\
.392 \\
.303 \\
.277 \\
.330 \\
.331 \\
.462 \\
.448 \\
.249 \\
.335\end{array}$ \\
\hline & Average & & & .276 & & & .282 & & & .316 & & & .355 \\
\hline $\begin{array}{l}\text { Total fringe count }(N) \\
((N \times \lambda)-0.710) / 2=\text { MPD } \\
\text { Etalon length at test temperature } \\
\text { Ball diameter at test temperature } \\
\text { Ball diameter at } 20^{\circ} \mathrm{C}\end{array}$ & $\begin{array}{l}\mu \\
\mu \\
\mu \\
\mu\end{array}$ & \multicolumn{3}{|c|}{$\begin{array}{c}12552.276 \\
3971.3237 \\
67471.5961 \\
63500.2724 \\
63500.0792\end{array}$} & \multicolumn{3}{|c|}{$\begin{array}{c}12552.282 \\
3971.3273 \\
67471.5956 \\
63500.2683 \\
63500.0860\end{array}$} & \multicolumn{3}{|c|}{$\begin{array}{c}12552.316 \\
3971.3329 \\
67471.5949 \\
63500.2620 \\
63500.0945\end{array}$} & \multicolumn{3}{|c|}{$\begin{array}{c}12552.355 \\
3971.3520 \\
67471.5948 \\
63500.2428 \\
63500.0769\end{array}$} \\
\hline
\end{tabular}
Values: Dia @ $20{ }^{\circ} \mathrm{C}=6.3500084 \mathrm{~cm}$ Vol. @ $20{ }^{\circ} \mathrm{C}=134.066888 \mathrm{~cm}^{3}$ 
TABLE 4c. Resume of raw data taken during interferometric tests on Ball C

$$
\begin{aligned}
& \text { Average test temperature }=20.2653{ }^{\circ} \mathrm{C} \\
& \text { Averaged measured diameter }=63500.1918 \mu \\
& \text { Averaged Measured MPD }=3971.4104 \mu
\end{aligned}
$$

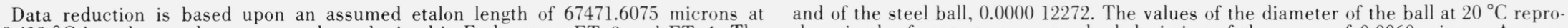

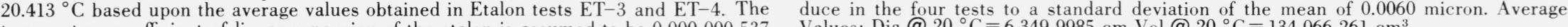
temperature coefficient of linear expansion of the etalon is assumed to be 0.000000537 Values: Dia @ $20{ }^{\circ} \mathrm{C}=6.3499985 \mathrm{~cm} \mathrm{Vol}_{0}$ @ $20{ }^{\circ} \mathrm{C}=134.066261 \mathrm{~cm}^{3}$

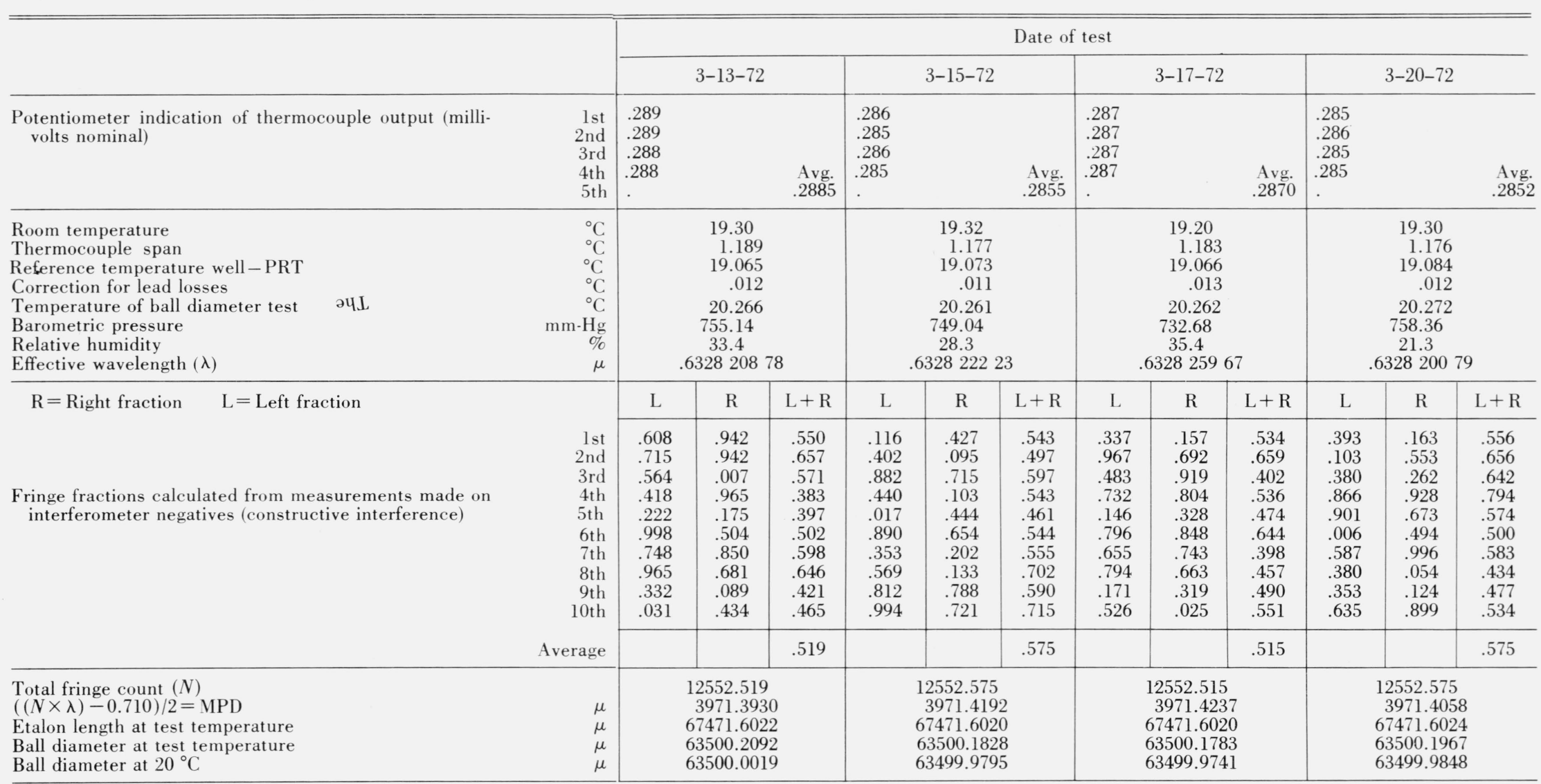


TABLE 4d. Resume of raw data taken during interferometric tests on Ball D

Average test temperature $=20.2678{ }^{\circ} \mathrm{C}$

Averaged measured diameter $=63500.3969 \mu$

Averaged Measured MPD $=3971.2054 \mu$

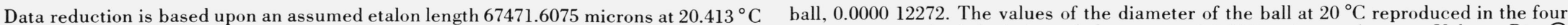

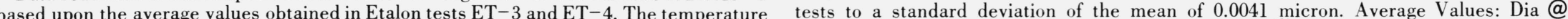
cofficient of linear expansion of the etalon is assumed to be 0.000000537 and of the steel $20{ }^{\circ} \mathrm{C}=6.3500188 \mathrm{~cm} \mathrm{Vol} @ 20{ }^{\circ} \mathrm{C}=134.067547 \mathrm{~cm} 3$

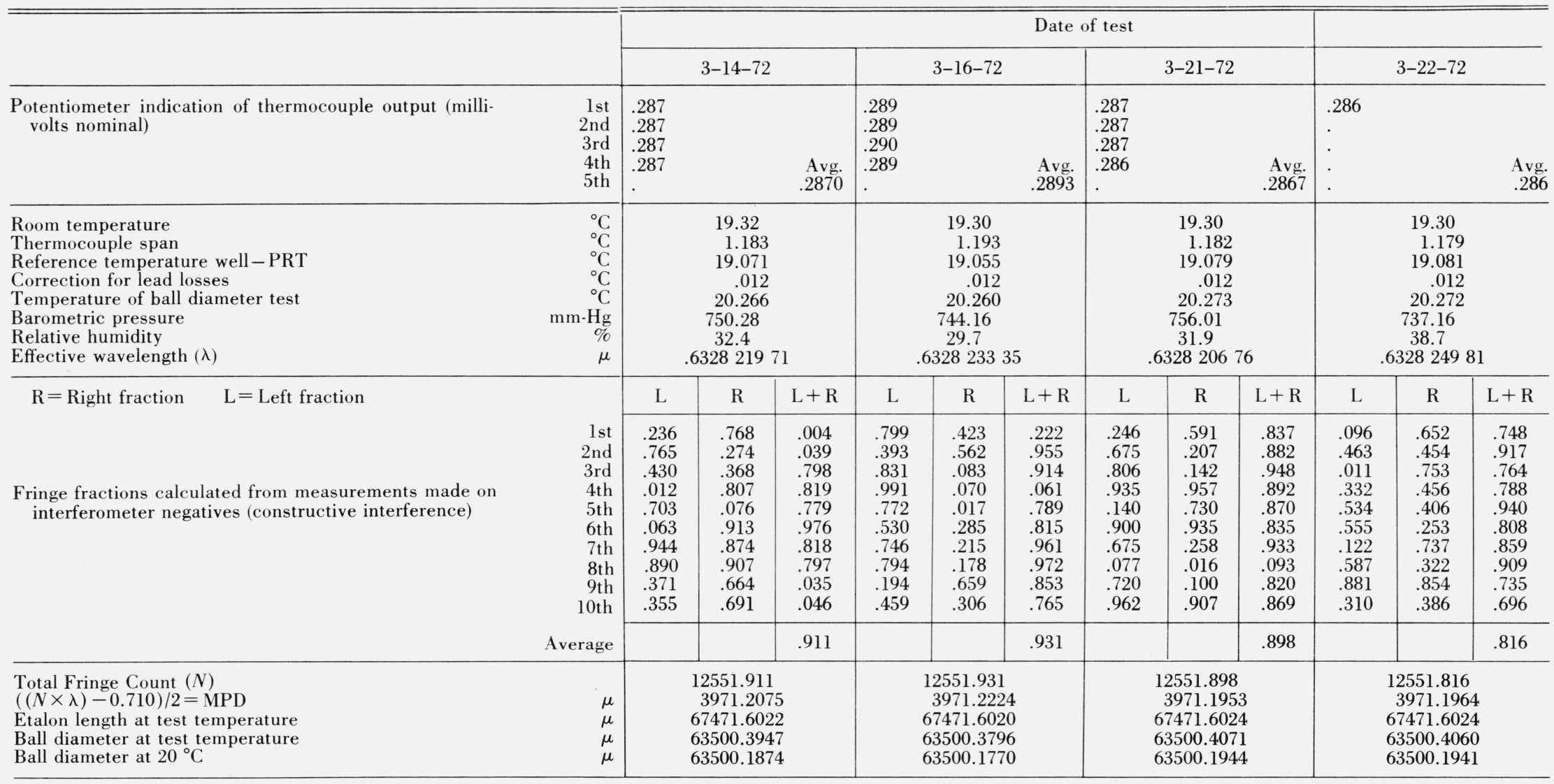


TABLE $4 \mathrm{e}$. Resume of raw data taken during interferometric tests on Ball E

Average test temperature $=22.8835{ }^{\circ} \mathrm{C}$
Averaged measured diameter $=63502.3533 \mu$
Averaged Measured MPD $=3969.3415 \mu$

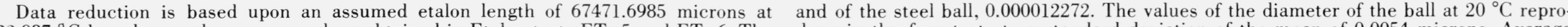

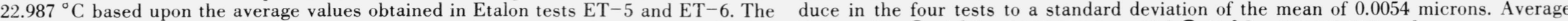
temperature coefficient of linear expansion of the etalon is assumed to be 0.000000537 Values: Dia @ $20{ }^{\circ} \mathrm{C}=6.3500106 \mathrm{~cm} \mathrm{Vol} @ 20{ }^{\circ} \mathrm{C}=134.067028 \mathrm{~cm}{ }^{3}$

\begin{tabular}{|c|c|c|c|c|c|c|c|c|c|c|c|c|c|}
\hline & & \multicolumn{12}{|c|}{ Date of test } \\
\hline & & \multicolumn{3}{|c|}{$5-3-72$} & \multicolumn{3}{|c|}{$5-8-72$} & \multicolumn{3}{|c|}{$5-11-72$} & \multicolumn{3}{|c|}{$5-11-72$} \\
\hline $\begin{array}{l}\text { Potentiometer indication of thermocouple output (milli- } \\
\text { volts nominal) }\end{array}$ & $\begin{array}{l}1 \text { st } \\
2 \text { nd } \\
3 \text { rd } \\
4 \text { th } \\
5 \text { th }\end{array}$ & $\begin{array}{l}.614 \\
.614 \\
.615 \\
.614 \\
.\end{array}$ & & $\begin{array}{l}\text { Avg. } \\
.6142\end{array}$ & $\begin{array}{l}.615 \\
.614 \\
.614 \\
.614 \\
.\end{array}$ & & $\begin{array}{l}\text { Avg. } \\
.6142\end{array}$ & $\begin{array}{l}.598 \\
.599 \\
.599 \\
.599 \\
.\end{array}$ & & $\begin{array}{l}\text { Avg. } \\
.5987\end{array}$ & $\begin{array}{l}.594 \\
.595 \\
.595 \\
.594 \\
.\end{array}$ & & $\begin{array}{l}\text { Avg. } \\
.5945\end{array}$ \\
\hline $\begin{array}{l}\text { Room temperature } \\
\text { Thermocouple span } \\
\text { Reference temperature well-PRT } \\
\text { Correction for lead losses } \\
\text { Temperature of ball diameter test } \\
\text { Barometric pressure } \\
\text { Relative humidity } \\
\text { Effective wavelength }(\lambda)\end{array}$ & $\begin{array}{r}{ }^{\circ} \mathrm{C} \\
{ }^{\circ} \mathrm{C} \\
{ }^{\circ} \mathrm{C} \\
{ }^{\circ} \mathrm{C} \\
{ }^{\circ} \mathrm{C} \\
{ }_{\%} \mathrm{Hg} \\
\mu\end{array}$ & \multicolumn{3}{|c|}{$\begin{array}{c}20.60 \\
2.532 \\
20.379 \\
.030 \\
22.941 \\
745.61 \\
42.2 \\
.632824672\end{array}$} & \multicolumn{3}{|c|}{$\begin{array}{c}20.50 \\
2.532 \\
20.361 \\
.032 \\
22.925 \\
747.91 \\
41.7 \\
.632824143\end{array}$} & \multicolumn{3}{|c|}{$\begin{array}{c}20.58 \\
2.468 \\
20.341 \\
.029 \\
22.838 \\
759.11 \\
23.9 \\
.632821449\end{array}$} & \multicolumn{3}{|c|}{$\begin{array}{c}20.60 \\
2.450 \\
20.351 \\
.029 \\
22.830 \\
758.66 \\
22.4 \\
.632821534\end{array}$} \\
\hline $\mathrm{R}=$ Right fraction $\quad \mathrm{L}=$ Left fraction & & $\mathrm{L}$ & $\mathrm{R}$ & $\mathrm{L}+\mathrm{R}$ & $\mathrm{L}$ & $\mathrm{R}$ & $\mathrm{L}+\mathrm{R}$ & $\mathrm{L}$ & $\mathrm{R}$ & $\mathrm{L}+\mathrm{R}$ & $\mathrm{L}$ & $\mathrm{R}$ & $\mathrm{L}+\mathrm{R}$ \\
\hline \multirow[t]{2}{*}{$\begin{array}{l}\text { Fringe fractions calculated from Measurements made on } \\
\text { interferometer negatives (constructive interference) }\end{array}$} & $\begin{array}{l}\text { 1st } \\
\text { 2nd } \\
3 \mathrm{rd} \\
4 \mathrm{th} \\
5 \mathrm{th} \\
6 \mathrm{th} \\
7 \mathrm{th} \\
8 \mathrm{th} \\
9 \mathrm{th} \\
10 \mathrm{th}\end{array}$ & $\begin{array}{l}.505 \\
.708 \\
.064 \\
.225 \\
.954 \\
.054 \\
.534 \\
.290 \\
.874 \\
.246\end{array}$ & $\begin{array}{l}.316 \\
.115 \\
.723 \\
.563 \\
.838 \\
.752 \\
.200 \\
.451 \\
.894 \\
.458\end{array}$ & $\begin{array}{l}.821 \\
.823 \\
.787 \\
.788 \\
.792 \\
.806 \\
.734 \\
.741 \\
.768 \\
.704\end{array}$ & $\begin{array}{l}.946 \\
.992 \\
.699 \\
.690 \\
.131 \\
.614 \\
.824 \\
.758 \\
.682 \\
.094\end{array}$ & $\begin{array}{l}.992 \\
.795 \\
.193 \\
.239 \\
.749 \\
.280 \\
.106 \\
.172 \\
.209 \\
.782\end{array}$ & $\begin{array}{l}.938 \\
.787 \\
.892 \\
.929 \\
.880 \\
.894 \\
.930 \\
.930 \\
.891 \\
.876\end{array}$ & $\begin{array}{l}.989 \\
.666 \\
.917 \\
.825 \\
.414 \\
.321 \\
.650 \\
.653 \\
.868 \\
.290\end{array}$ & $\begin{array}{l}.155 \\
.520 \\
.273 \\
.320 \\
.720 \\
.859 \\
.448 \\
.557 \\
.244 \\
.863\end{array}$ & $\begin{array}{l}.144 \\
.186 \\
.190 \\
.145 \\
.134 \\
.180 \\
.098 \\
.210 \\
.112 \\
.153\end{array}$ & $\begin{array}{l}.230 \\
.544 \\
.807 \\
.982 \\
.178 \\
.935 \\
.853 \\
.565 \\
.359 \\
.183\end{array}$ & $\begin{array}{l}.988 \\
.569 \\
.348 \\
.116 \\
.993 \\
.199 \\
.317 \\
.566 \\
.790 \\
.982\end{array}$ & $\begin{array}{l}.218 \\
.113 \\
.155 \\
.098 \\
.171 \\
.134 \\
.170 \\
.131 \\
.149 \\
.165\end{array}$ \\
\hline & Average & & & .776 & & & .895 & & & .156 & & & .150 \\
\hline $\begin{array}{l}\text { Total fringe count }(N) \\
((N \times \lambda)-0.710) / 2=\text { MPD } \\
\text { Etalon length at test temperature } \\
\text { Ball diameter at test temperature } \\
\text { Ball diameter at } 20^{\circ} \mathrm{C}\end{array}$ & $\begin{array}{l}\mu \\
\mu \\
\mu \\
\mu\end{array}$ & \multicolumn{3}{|c|}{$\begin{array}{c}12545.776 \\
3969.2833 \\
67471.6969 \\
63502.4136 \\
63500.1217\end{array}$} & \multicolumn{3}{|c|}{$\begin{array}{c}12545.895 \\
3969.3176 \\
67471.6963 \\
63502.3787 \\
63500.0993\end{array}$} & \multicolumn{3}{|c|}{$\begin{array}{r}12546.156 \\
3969.3833 \\
67471.6931 \\
63502.3098 \\
63500.0982\end{array}$} & \multicolumn{3}{|c|}{$\begin{array}{r}12546.150 \\
3969.3819 \\
67471.6928 \\
63502.3109 \\
63500.1055\end{array}$} \\
\hline
\end{tabular}


TABLE 4f. Resume of raw data taken during interferometric tests on Ball F

$$
\begin{aligned}
& \text { Average test temperature }=22.9153^{\circ} \mathrm{C} \\
& \text { Averaged measured diameter }=63502.3682 \mu \\
& \text { Averaged Measured MPD }=3969.3278 \mu
\end{aligned}
$$

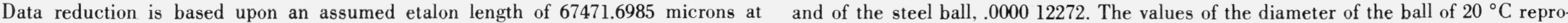

\begin{tabular}{|c|c|c|c|c|c|c|c|c|c|c|c|c|c|}
\hline & & \multicolumn{12}{|c|}{ Date of test } \\
\hline & & \multicolumn{3}{|c|}{$5-2-72$} & \multicolumn{3}{|c|}{$5-2-72$} & \multicolumn{3}{|c|}{$5-4-72$} & \multicolumn{3}{|c|}{$5-10-72$} \\
\hline $\begin{array}{l}\text { Potentiometer indication of thermocouple output (milli- } \\
\text { volts nominal) }\end{array}$ & $\begin{array}{l}\text { lst } \\
\text { 2nd } \\
\text { 3rd } \\
4 \text { th } \\
5 \text { th }\end{array}$ & $\begin{array}{l}.604 \\
.604 \\
.605 \\
.604 \\
.\end{array}$ & & $\begin{array}{l}\text { Avg. } \\
.6042\end{array}$ & $\begin{array}{l}.604 \\
.604 \\
.604 \\
.604 \\
.\end{array}$ & & $\begin{array}{l}\text { Avg. } \\
6040\end{array}$ & $\begin{array}{l}.616 \\
.616 \\
.616 \\
.616 \\
.\end{array}$ & & $\begin{array}{l}\text { Avg. } \\
.6160\end{array}$ & $\begin{array}{l}.596 \\
.596 \\
.596 \\
.596 \\
. \quad\end{array}$ & & $\begin{array}{l}\text { Avg. } \\
.5960\end{array}$ \\
\hline $\begin{array}{l}\text { Room temperature } \\
\text { Thermocouple span } \\
\text { Reference temperature well-PRT } \\
\text { Correction for lead losses } \\
\text { Temperature of ball diameter test } \\
\text { Barometric pressure } \\
\text { Relative humidity } \\
\text { Effective wavelength }(\lambda)\end{array}$ & $\begin{array}{r}{ }^{\circ} \mathrm{C} \\
{ }^{\circ} \mathrm{C} \\
{ }^{\circ} \mathrm{C} \\
{ }^{\circ} \mathrm{C} \\
{ }^{\circ} \mathrm{C} \\
\mathrm{mm} \cdot{ }_{\%} \\
\mu\end{array}$ & \multicolumn{3}{|c|}{$\begin{array}{c}20.70 \\
2.490 \\
20.421 \\
.029 \\
22.940 \\
748.21 \\
42.3 \\
.632824089\end{array}$} & \multicolumn{3}{|c|}{$\begin{array}{c}20.70 \\
2.489 \\
20.421 \\
.029 \\
22.939 \\
748.11 \\
41.6 \\
.632824106\end{array}$} & \multicolumn{3}{|c|}{$\begin{array}{c}20.50 \\
2.539 \\
20.369 \\
.032 \\
22.940 \\
746.98 \\
36.5 \\
.632824321\end{array}$} & \multicolumn{3}{|c|}{$\begin{array}{c}20.60 \\
2.456 \\
20.357 \\
.029 \\
22.842 \\
754.06 \\
32.0 \\
.632822643\end{array}$} \\
\hline $\mathrm{R}=$ Right fraction $\quad \mathrm{L}=$ Left fraction & & $\mathrm{L}$ & $\mathrm{R}$ & $\mathrm{I}+\mathrm{R}$ & $\mathrm{L}$ & $\mathrm{R}$ & $\mathrm{L}+\mathrm{R}$ & $\mathrm{L}$ & $\mathrm{R}$ & $\mathrm{L}+\mathrm{R}$ & $\mathrm{L}$ & $\mathrm{R}$ & $\mathrm{L}+\mathrm{R}$ \\
\hline \multirow[t]{2}{*}{$\begin{array}{l}\text { Fringe fractions calculated from measurements made on } \\
\text { interferometer negatives (constructive interference) }\end{array}$} & $\begin{array}{r}1 \mathrm{st} \\
2 \mathrm{nd} \\
3 \mathrm{rd} \\
4 \mathrm{th} \\
5 \mathrm{th} \\
6 \mathrm{th} \\
7 \mathrm{th} \\
8 \mathrm{th} \\
9 \mathrm{th} \\
10 \mathrm{th}\end{array}$ & $\begin{array}{l}.747 \\
.139 \\
.441 \\
.285 \\
.947 \\
.126 \\
.244 \\
.090 \\
.658 \\
.866\end{array}$ & $\begin{array}{l}.183 \\
.727 \\
.432 \\
.527 \\
.853 \\
.579 \\
.547 \\
.866 \\
.166 \\
.011\end{array}$ & $\begin{array}{l}.930 \\
.866 \\
.873 \\
.812 \\
.800 \\
.705 \\
.791 \\
.956 \\
.824 \\
.877\end{array}$ & $\begin{array}{l}.609 \\
.796 \\
.293 \\
.401 \\
.535 \\
.280 \\
.379 \\
.560 \\
.960 \\
.424\end{array}$ & $\begin{array}{l}.224 \\
.107 \\
.521 \\
.475 \\
.223 \\
.591 \\
.395 \\
.207 \\
.964 \\
.388\end{array}$ & $\begin{array}{l}.833 \\
.903 \\
.814 \\
.876 \\
.758 \\
.871 \\
.774 \\
.767 \\
.924 \\
.812\end{array}$ & $\begin{array}{l}.595 \\
.054 \\
.465 \\
.969 \\
.853 \\
.901 \\
.130 \\
.689 \\
.351 \\
.341\end{array}$ & $\begin{array}{l}.332 \\
.848 \\
.365 \\
.951 \\
.013 \\
.006 \\
.721 \\
.173 \\
.490 \\
.388\end{array}$ & $\begin{array}{l}.927 \\
.902 \\
.830 \\
.920 \\
.866 \\
.907 \\
.851 \\
.862 \\
.841 \\
.929\end{array}$ & $\begin{array}{l}.477 \\
.482 \\
.077 \\
.663 \\
.201 \\
.632 \\
.150 \\
.834 \\
.910 \\
.002\end{array}$ & $\begin{array}{l}.772 \\
.744 \\
.086 \\
.523 \\
.980 \\
.582 \\
.941 \\
.409 \\
.189 \\
.102\end{array}$ & $\begin{array}{l}.249 \\
.226 \\
.163 \\
.186 \\
.181 \\
.214 \\
.091 \\
.243 \\
.099 \\
.104\end{array}$ \\
\hline & Average & & & .843 & & & .833 & & & .884 & & & .176 \\
\hline $\begin{array}{l}\text { Total fringe count }(N) \\
((N \times \lambda)-0.710) / 2=\text { MPD } \\
\text { Etalon length at test temperature } \\
\text { Ball diameter at test temperature } \\
\text { Ball diameter at } 20^{\circ} \mathrm{C}\end{array}$ & $\begin{array}{l}\mu \\
\mu \\
\mu \\
\mu\end{array}$ & \multicolumn{3}{|c|}{$\begin{array}{c}12545.843 \\
3969.3008 \\
67471.6968 \\
63502.3960 \\
63500.1050\end{array}$} & \multicolumn{3}{|c|}{$\begin{array}{c}12545.833 \\
3969.2978 \\
67471.6968 \\
63502.3990 \\
63500.1086\end{array}$} & \multicolumn{3}{|c|}{$\begin{array}{r}12545.884 \\
3969.3153 \\
67471.6968 \\
63502.3815 \\
63500.0904\end{array}$} & \multicolumn{3}{|c|}{$\begin{array}{l}12546.176 \\
3969.3971 \\
67471.6933 \\
63502.2962 \\
63500.0814\end{array}$} \\
\hline
\end{tabular}

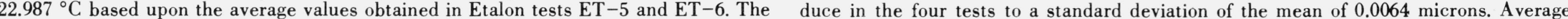
temperature coefficient of linear expansion of the etalon is assumed to be .000000537 Values: Dia @ $20{ }^{\circ} \mathrm{C}=6.3500096 \mathrm{~cm} \mathrm{Vol} \mathrm{@} 20{ }^{\circ} \mathrm{C}=134.066966 \mathrm{~cm}^{3}$ 
where $t_{1}$ is the lower temperature and $t_{2}$ the higher. We have measured the MPD of balls A and B at about $20.2{ }^{\circ} \mathrm{C}$ and (under the names $\mathrm{E}$ and $\mathrm{F}$ ) at about 23 ${ }^{\circ} \mathrm{C}$ and presented the data in table 4 . By this procedure we estimate the coefficient of $\mathrm{A}$ to be 0.000 012220 and B to be 0.000012324 .

The manufacturer believes the coefficients of the balls (whatever their magnitude) to be about equal because they were from the same metallurgical stock, subjected to the same heat treatment and same mechanical surface work. Accordingly, we have averaged the above two values and applied this average, 000012272 to all balls.

\subsection{Hydrostatic Transfer of Volumetric Information from the Spheres to the Crystals}

Several years ago, BIPM circulated a one-kilogram metal object among the major national metrology laboratories for a density determination. The spread of data among this very sophisticated group amounted to about $14 \mathrm{ppm}$. Although part of this spread could most certainly be ascribed to differences in density of the water samples used, we have always believed (without proof) that this was another demonstration of the basic imprecision of the classical hydrostatic weighing experiment. In spite of the shortcomings of this experiment, nobody has suggested a more precise procedure for routine density comparisons. Although the thermal Cartesian Diver of Spaepen [13] and the pressure Cartesian Diver of Bowman and Schoonover [6] are about two orders more precise than ordinary hydrostatic weighing, the complexity of such systems immediately eliminates them from the "routine" category.

The volumetric information contained in our spheres was too dear to us to dissipate unnecessarily in the imprecision of a classical hydrostatic transfer experiment, so we had previously devoted a great deal of effort to improving this precision. We have found it expedient to modify both the hydrostatic system and the experimental philosophy.

\subsubsection{The Hydrostatic System}

There are four components of the hydrostatic weighing system: (1) the suspension, (2) the liquid, (3) the immersed pan loading assembly, and (4) the hydrostatic balance. Each component contributes to imprecision; but if choices are made with care, total variability may be restricted to reasonable bounds.

\subsubsection{The Hydrostatic Suspension}

This is the member which delivers the load from the immersed structure to the balance. Its most critical component is the suspension wire which passes through the air-liquid interface. Inasmuch as we have already published [14] a procedure for reducing variability from this source to a few micrograms it will not be commented upon here.

$$
\text { 2.5.1.2. The Hydrostatic Liquid }
$$

The intent of the hydrostatic weighing experiment is accomplished by observing the buoyant force exerted on the object of interest by the liquid. The liquid exerts two independent effects on the precision of the experiment. The greater its density, the greater is the magnitude of the buoyant force exerted by the liquid, and the easier it is to measure in the presence of many small perturbing forces. The liquid we have chosen is a fluorocarbon whose density $\left(1.8 \mathrm{~g} / \mathrm{cm}^{3}\right)$ is almost twice that of water so that precision is almost doubled. This substance has been used in this service for many years by atomic reactor experimenters and it has proved to be an excellent choice.

One of the major perturbing forces associated with the use of water arises from its large and variable surface tension. The penetration wire minimizes most of these effects when it is skillfully prepared. The fluorocarbon we use has a surface tension only about one fifth that of water (15 versus $75 \mathrm{dyn} / \mathrm{cm}$ ) which has the effect of improving wire performance even if incorrectly or sloppily prepared.

An additional major advantage of this liquid is its vast appetite for absorbing gas. This gives a great deal of protection against variability associated with surface bound tiny bubbles on immersed loads.

\subsubsection{The Immersed Pan Loading Assembly-Redundancy}

A time honored technique for minimizing random variability in a process is to make "many" independent observations.

In comparing two quantities the experimenter has available only one comparison combination. In working with three quantities he has only three combinations. When he works with four quantities he has six combinations, and under these circumstances he has the redundancy necessary to make a meaningful reduction in random variability.

Figure 5 is a schematic sketch of our immersed pan loading assembly, from which it is obvious that we

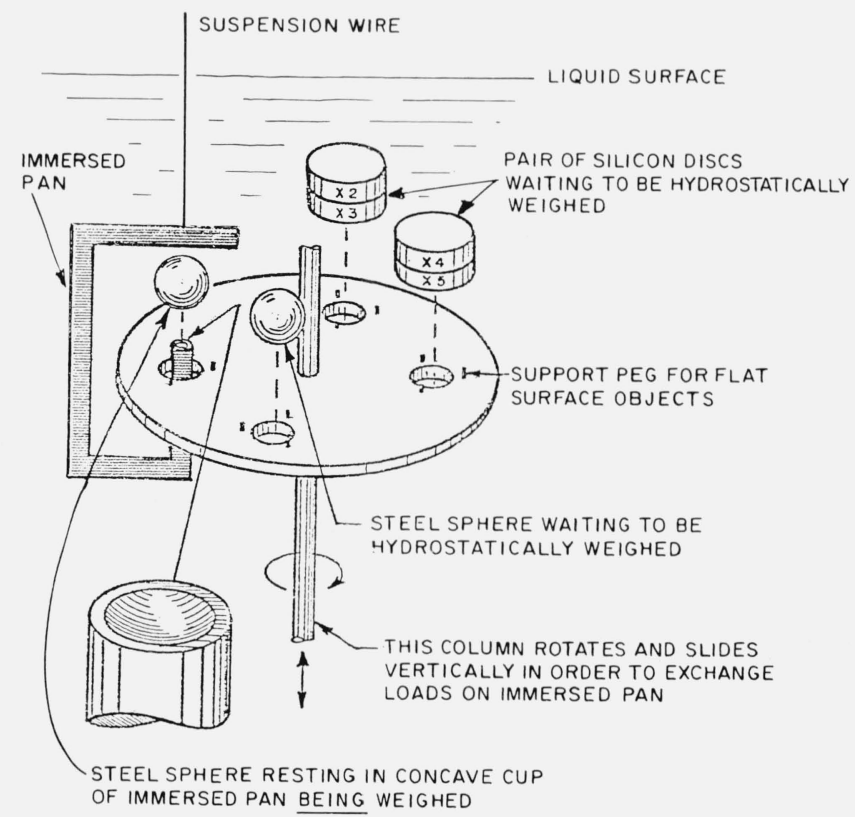

FIGURE 5. Immersed pan loading mechanism. 
are able to compare four different loads in a single experiment. The sketch shows two of the loading trays carrying two silicon crystals each, a third tray carrying ball $\mathrm{B}$ and the fourth tray (which normally carries ball A) empty, inasmuch as ball $\mathrm{A}$ is on the immersed pan.

With the apparatus loaded as illustrated we may compare the four loads (two balls and two pairs of silicon crystals) in all six combinations. This comparison format is called a 4-1 series and is the format used throughout this work. It should be noted that by varying the combinations of loading that many different 4-1 series may be conducted on the same two balls and four crystals. We utilized the four combinations shown below:

\begin{tabular}{c|c|c|c}
\hline \hline TRAY 1 & TRAY 2 & TRAY 3 & TRAY 4 \\
\hline BALL A & BALL B & X2+X3 & X4+ X5 \\
BALL A & BALL B & X2+X4 & X3+ X5 \\
BALL A & BALL B & X2+ X5 & X3+ X4 \\
X2 & X3 & X4 & X5 \\
\hline
\end{tabular}

2.5.1.4. The Hydrostatic Balance and Its Calibration

Other factors being equal, the data spread among independently measured densities decreases with increasing sample size. In our 1967 paper on hydrostatic weighing in water, we demonstrated that a singlepan, damped, direct-reading balance would provide density values spreading by $3 \mathrm{ppm}$ (worse case) for 10 cubic centimeter samples. This was significantly better than our previous work using a free-swinging, equal-arm balance. For this reason, and others mentioned in that paper, we abandoned the conventional balance, and since that time, all critical density work at NBS has been performed on single-pan, directreading instruments.

In 1967 we recommended the single-pan directreading balance as the best available instrument and, to date, we have found no evidence to suggest a change in this position. We have used two balances of this type in the work reported here. In the earlier paper we speculated upon the ideal hydrostatic balance (servodriven-to-null) and we have commenced development of such a device. We feel confident that this balance will improve the hydrostatic experiment by about an order of magnitude. Until this device is complete we shall continue use of the simple instrument.

In informal and unreported experiments on conventional freeswinging equal-arm balances we found several modifications which would improve their hydrostatic precision. The application of strong vertical temperature gradients in the balance case as described by Macurdy, NBS, [15] reduced random variability. The application of external damping was even more effective. Reducing sensitivity (by lowering the gravity knob) to the point where readability and reproducibility were about equal actually improved the latter. The use of a large-volume hydrostatic chamber appeared to give higher precision data than small chambers.

We believe that the vertical oscillations of an immersed load suspended from a free-swinging balance are damped by the viscous action of the liquid on the load. During this process, momentum is transferred from the oscillating system to the liquid where it manifests itself as turbulence. This turbulence results in faulty "turning point" data. We believe that system damping should be such that momentum is removed completely from the hydrostatic system such as is true for damping by air or magnetic eddy currents and the heavier this damping, up to near critical, the better because the quicker the oscillations are damped to zero, the less the turbulence in the liquid.

We believe that by the judicious use of the techniques mentioned above and perhaps some others, hydrostatic work on the free swinging balance could be significantly improved. Considering the relative ease of achieving ppm results with a direct-reading balance, it is questionable whether the required expenditure of effort would be justified.

In the single-arm direct-reading damped balance, the maximum vertical motion of the suspension is about 3 millimeters, and the motion is quickly damped externally to near zero. In a balance of this type, built-in balance weights may be added to or removed from the suspension by remote control dials which cause only slight motion being induced in the bath.

Commercially available single-pan direct-reading balances are intended for use in the air weighings mode, and in such service they satisfy most weighing requirements. When they are put to use in the hydrostatic mode it is necessary that the direct-reading data be interpreted in a slightly different manner in the data reduction process. The data are obtained from the balance by means of two devices - the numbers engraved on the weight changing dial(s) and the numbers projected on a screen from a highly magnified view of a small reticle attached to the beam counterweight system.

1. SCREEN READINGS. The manufacturer of the balance assigns mass designations to the screen readings which are appropriate for use in the air weighing mode. These designations are based upon assumptions regarding the density of the objects to be weighed and that the only screen-related force in the system is associated with beam-angle moments. In the hydrostatic mode there must necessarily be a wire penetrating the liquid surface. The dip section of this wire (the section which is sometimes immersed in the bath and sometimes exposed to air) exerts two forces on the suspension system - a constant force and also a force which is directly proportional to the screen reading. Although neither of these forces have to be evaluated independently, as will be shown in the section following, the screen-related force demands that we interpret the screen readings merely as numbers indicating the angle of the beam counterweight system. This interpretation satisfies all requirements of the double substitution force comparison solution given in the next section.

2. THE DIAL READINGS. The numbers engraved on the weight manipulation dials are intended for use in direct-weighing in air of loads placed on the weighing pan. In the air weighing situation they indicate (in units of apparent mass versus brass [16]) the mass of balance weights removed from the suspension. In the calibration procedure it is necessary to determine the true mass of weights actually loading the suspension for each dial reading to make a true comparison between the forces associated with an immersed load and those associated with the built-in balance weights (in air). There are two methods of obtaining a calibration. The easiest is by weighing standard weights on 
the pan of the balance. This was discussed in our 1967 paper. The other technique is to remove the weights from the balance and calibrate them in the same manner that one would use in the calibration of any other standard weight.

A requirement of a direct-reading balance to be used in hydrostatic work is that the major weights of the balance have densities equal to a few parts in $10^{4}$. Most manufacturers meet this requirement. We verified by experiment that this requirement was satisfied in the balances used in our work.

When the hydrostatic balance is to be used in the most critical work, the built-in weights should be calibrated in two steps:

1. All weights should be removed from the balance and the total mass (of the summation) should be determined. Out of this test we obtain a value of the correction to the nominal value of the summation and an estimate of the uncertainty in this value.

2. The balance weights should then be intercompared in combinations which permit a calculation of the fraction of the summation mass contained in each individual balance weight.

\subsubsection{Hydrostatic Weighing on a Direct-Reading Balance}

Our objective in hydrostatically weighing an object is to obtain a value of $I$, defined as

$$
I=M-\rho_{L} V
$$

where $M$ and $V$ are the mass and volume respectively of the object and $\rho_{L}$ the density of the liquid.

For several years we have determined $I$ from a double substitution comparison between the (unknown) force associated with the immersed load and the (known) force associated with the built-in weights of a single-arm direct-reading balance. The format which we use in making this comparison consists of five balance observations under various load conditions. The entire comparison requires four minutes because, we have found, results are most reproducible when there is a one minute interval between observations. The five load conditions are:

1. With the immersed pan empty

2. With the immersed pan loaded by the object of interest

3. With the sensitivity weight added (in air)

4. With the load removed from the immersed pan

5. With the sensitivity weight removed-the first and fifth load conditions are the same.

Each observation requires the recording of two data (1) the dial reading which indicates the combination of the built-in balance weights which are in place and loading the suspension, (2) the screen reading which is taken as a number indicating the beam-counterweight angle with respect to some fixed reference. As pointed out in the previous section, this is not the interpretation placed on direct-reading balance data in the ordinary weighing situation.
In the first, fourth and fifth observations, taken with the immersed pan empty, the dial readings will be the same $\left(D_{i}=D_{0}\right)$, and in the second and third, with the immersed pan loaded $\left(D_{i}=D_{L}\right)$. The five screen readings, $s_{1}$ to $s_{5}$, are usually different. The balance data are therefore of the form

$$
\begin{aligned}
& D_{0}, s_{1} \\
& D_{L}, s_{2} \\
& D_{L}, s_{3} \\
& D_{0}, s_{4} \\
& D_{0}, s_{5}
\end{aligned}
$$

In our 1967 paper [14] on hydrostatic weighing we presented a detailed discussion of the linearity between the beam angle and changes in the total suspension force. We described how the linearity may be evaluated in a simple experiment and how to correct observed data if linearity was judged to be inadequate. Since the date of that paper, we have evaluated several single-arm, direct-reading balances, and we have not found any to be inadequately linear for hydrostatic work.

Subject to the following assumptions, we may write equations associated with suspension forces under each of the five load conditions listed above:

1. That the beam angle, as defined by screen readings, is a linear indicator of the difference between the total suspension force and a fixed reference force associated with the counter-weight system.

2. That prior calibration effort has provided us with knowledge of the true mass and density of each of the three balance weights involved in the double-substitution comparison. These three weights are:

a. $D_{0}$-the combination of balance weights loading the suspension when the dial reads $D_{0}$.

b. $D_{L}$-the combination of balance weights loading the suspension when the dial reads $D_{L}$.

c. $S$-the sensitivity weight.

3. That the density, $\rho_{B}$, of these three weights is equal.

4. That the following parameters are constant during the four minute observation interval:

a. The air density, $\rho_{A}$, in the balance case.

b. The bath density, $\rho_{L}$.

c. The volume and density of the meniscus.

5. That there are no perturbing turbulent forces.

6 . That the drift in the system is linear with time.

The five observation equations to be written consist of various combinations of forces. With the exception of the unknown force exerted by the immersed load, $I g$ (where $g$ is the acceleration due to gravity at the immersed pan level) these forces fall into three classes:

1. Forces which are constant over the observation interval. These forces need not be evaluated because they are eliminated during the solution of the system 
of observation equations. They may be added directly and the value of $C$ assigned to their sum. These forces are:

a. The force exerted by the portion of the suspension which is never immersed in the bath.

b. The forces exerted by the portion of the suspension which is always immersed.

c. The constant component of force exerted by the dip section of the suspension wire.

d. The reference force.

e. The meniscus force.

2. Forces which are linearily related to the beam angle (and hence the screen reading). There are two such forces:

a. $K_{1} s_{i}$, where $K_{1}$ is the proportionality constant between the screen reading, $s_{i}$, and the difference between the constant reference force and the total suspension force.

b. $K_{2} s_{i}$, where $K_{2}$ is the proportionality constant between the screen reading, $s_{i}$, and the component of force exerted by the dip section of the suspension wire which is screen related.

These two forces need not be previously evaluated because they are added together as

$$
K s_{i}=K_{1} s_{i}+K_{2} s_{i}
$$

and are evaluated (as a sum) during the solution of the system of observation equations.

3 . The forces which are exerted by the three balance weights involved in the comparison. These three forces are:

$$
\begin{gathered}
F_{D 0}=M_{D 0}\left[1-\frac{\rho_{A}}{\rho_{B}}\right] g_{1} \\
F_{D L}=M_{D L}\left[1-\frac{\rho_{A}}{\rho_{B}}\right] g_{1} \\
F_{S}=M_{S}\left[1-\frac{\rho_{A}}{\rho_{B}}\right] g_{1}
\end{gathered}
$$

where $g_{1}$ is the acceleration due to gravity at the vertical level in the balance case in which the balance weights are loaded on the suspension.

The five observation equations and a method of solving them for the value of $I$ are as follows:

$$
\begin{array}{ll}
\text { 1. } C+F_{D 0} & =s_{1} K \\
\text { 2. } C+F_{D L}+I g & =s_{2} K \\
\text { 3. } C+F_{D L}+I g+F_{S} & =s_{3} K \\
\text { 4. } C+F_{D 0}+F_{S} & =s_{4} K \\
\text { 5. } C+F_{D 0} & =s_{5} K
\end{array}
$$

Subtracting eq (1) from eq (2) gives us a value of $I g$ in terms of $K$. Subtracting eq (2) from eq (3) provides us with a value of $K$ so that we may write our first value of $I g$ from the double substitution force comparison

$$
I^{\prime} g=F_{D 0}-F_{D L}+F_{S}\left[\frac{s_{2}-s_{1}}{s_{3}-s_{2}}\right] .
$$

A similar manipulation of eqs (3), (4), and (5) gives us the second value

$$
I^{\prime \prime} g=F_{D 0}-F_{D L}+F_{S}\left[\frac{s_{3}-s_{4}}{s_{4}-s_{5}}\right]
$$

Letting

$$
s=\frac{\frac{s_{2}-s_{1}}{s_{3}-s_{2}}+\frac{s_{3}-s_{4}}{s_{4}-s_{5}}}{2}
$$

we may write the average value of $I g$ which is used during data reduction

$$
I g=\frac{I^{\prime} g+I^{\prime \prime} g}{2}=F_{D 0}-F_{D L}+F_{S} s .
$$

Replacing the right member force terms by their calibration data gives us the numerical value of $I$ which the experiment is designed to provide

$$
I=\left[M_{D 0}-M_{D L}+M_{S} s\right]\left[1-\frac{\rho_{A}}{\rho_{B}}\right]\left[\frac{g_{1}}{g}\right]
$$

An adequate value of $g_{1}$ is obtained from geometric measurements on the system and assumed values of $g$ and the vertical gradient in $g$. As pointed out in the previous section, there are two methods of calibrating a direct-reading balance. If the weights are removed from the balance for calibration, $g_{1}$ is the value of the acceleration due to gravity at the level in the suspension where the weights actually load it. On the other hand, if the weights are calibrated in place by weighing standard weights on the load pan of the balance, the effective level at which $g_{1}$ should be calculated is the level of the load pan in the weighing chamber of the balance.

In the foregoing solution for $I$, we initially obtain two values of $I g$, namely $I^{\prime} g$ and $I^{\prime \prime} g$. These two values should be very nearly equal. A wide separation of the two values probably indicates failure to meet the six assumptions upon which the solution depends. We believe the $I^{\prime} g-I^{\prime \prime} g$ may be an excellent quality control signal, but we have not yet had the long experience with our system which is necessary to evaluate it as such.

\subsubsection{Hydrostatic Weighing Format - The 4-1 Ratio Series}

The equation

$$
I_{\mathrm{A}}=M_{\mathrm{A}}-\rho_{L} V_{\mathrm{A}}
$$

where the subscript $\mathrm{A}$ indicates that object $\mathrm{A}$ is under test, is classically solved for $V_{\mathrm{A}}$ based upon measured values of $I_{\mathrm{A}}$ and $M_{\mathrm{A}}$ and a tabulated value of $\rho_{L}$. 
This is not our intent. By use of the immersed pan loading assembly, 2.5.1.3, we remove object $\mathrm{A}$ from the immersed pan and replace it with object B. This results in violent turbulence in the bath, so we wait 10 minutes for the bath motion to subside, after which we perform the 5 observations required to obtain a value of

$$
I_{\mathrm{B}}=M_{\mathrm{B}}-\rho_{L} V_{\mathrm{B}}
$$

These two equations may be combined to provide us with a value of the volumetric ratio of object $A$ to object B

$$
\frac{V_{\mathrm{A}}}{V_{\mathrm{B}}}=\frac{M_{\mathrm{A}}-I_{\mathrm{A}}}{M_{\mathrm{B}}-I_{\mathrm{B}}} .
$$

Combining the hydrostatically measured values of $I_{\mathrm{A}}$ and $I_{\mathrm{B}}$ with previously determined values of $M_{\mathrm{A}}$ and $M_{\mathrm{B}}$ yields a numerical value of the volumetric ratio at the temperature of the experiment. The validity of the ratio is primarily limited by the nonlinear drift in the system. The linear component is accounted for by performing the hydrostatic weighings in a timesymmetrical $\mathrm{A}-\mathrm{B}-\mathrm{A}$ format.

Inasmuch as our immersed pan loading assembly will manipulate 4 objects, we may compare them in six combinations. This requires 15 hydrostatic weighings taken if the following order:

$$
\mathrm{A}-\dot{\mathrm{B}}-\mathrm{A}-\mathrm{C}-\mathrm{A}-\mathrm{D}-\mathrm{A}-\mathrm{B}-\mathrm{C}-\mathrm{B}-\mathrm{D}-\mathrm{B}-\mathrm{C}-\mathrm{D}-\mathrm{C} \text {. }
$$

This is not a perfectly balanced series because object D is weighed only three times while all other objects are weighed four times; however it is adequate to define the six ratios in $\mathrm{A}-\mathrm{B}-\mathrm{A}$ type formats.

A 4-1 series ordinarily provides us with six differences. In the case at hand we obtain six ratios, and in this case, the series is referred to as a 4-1 ratio series.

The 15 weighings to be performed are then calculated as six 1-2-1 comparisons of volumes.

A-B-A gives us the volumetric ratio $\frac{A}{B}$

A-C-A gives us the volumetric ratio $\frac{A}{C}$

A-D-A gives us the volumetric ratio $\frac{A}{D}$

B-C-B gives us the volumetric ratio $\frac{B}{C}$

B-D-B gives us the volumetric ratio $\frac{B}{D}$

C-D-C gives us the volumetric ratio $\frac{C}{D}$

This procedure may be interrupted at any time between 1-2-1 comparisons, however this usually requires one additional observation to maintain the time symmetrical properties of each comparison.
In actual practice, all 15 tests which make up the 4-1 ratio series are conducted at slightly different temperatures. Unless the objects under volumetric comparison have the same temperature coefficients of expansion, their ratio will be a function of the temperature of observation. Therefore, before proceeding with the least-squares adjustment of this series, we reduce the observed ratio at the temperature of the test to the ratio which would exist at $20^{\circ} \mathrm{C}$ by appropriate application of the temperature coefficients of expansion of the objects.

We use the method of Connor and Youden, NBS, [17] for least-squares adjustment. They noted that the products of the observed ratios

$$
\begin{aligned}
& \frac{A}{B} X \frac{B}{C} X \frac{C}{A} \\
& \frac{A}{B} X \frac{B}{D} X \frac{D}{A} \\
& \frac{A}{C} X \frac{C}{D} X \frac{D}{A} \\
& \frac{B}{C} X \frac{C}{D} X \frac{D}{B}
\end{aligned}
$$

as well as some four-ratio-products would be exactly equal to unity if the series were performed without error. These observed ratios may be adjusted by least squares to values which actually do have unity products by their formula of the form

$$
\frac{\hat{\boldsymbol{A}}}{\hat{B}}=\sqrt[4]{\left[\frac{A}{B}\right]^{2}\left[\frac{A}{C} X \frac{C}{B}\right]\left[\frac{A}{D} X \frac{D}{B}\right]}
$$

where the overlined values, eg., $\frac{\hat{A}}{\hat{B}}$, are adjusted ratios. The absolute sum of the six residual differences between the observed and adjusted ratios is a measure of the precision of the conduct of the 4-1 ratio series.

As pointed out in 2.5.1.3 we are able to conduct four different 4-1 ratio series on the two standard balls and four crystals. The observed ratios, 24 in all, are presented in tables 5 . Also shown in the table are the ratios reduced to $20^{\circ} \mathrm{C}$, their adjusted values from the Connor-Youden procedure, and the sum of the residuals.

In 2.5.2 it was shown that the mass of the objects enters the calculation of the volumetric ratios, so the assumed values of the masses and coefficients of expansion of the six objects are given in the caption to the tables 5 .

\subsection{Final Calculation of Crystal Volumes and Densities}

The 24 ratios shown in the last column of table 5 may each be used in writing an equation expressing the relative volume between various members of the 
This table presents the volumetric ratios between the four silicon crystals and the two steel balls employed in Determination AB. As pointed out in the test the "ratios at test temperature" are calculated from the previously measured mass value and the weight in liquid measured hydrostatically. The ratios at $20^{\circ} \mathrm{C}$ involve assumed values of temperature coefficients of expansion. These assumed masses and coefficients are given below. These ratios at $20^{\circ} \mathrm{C}$ are submitted (in groups of six) to the Connor-Youden least square adjustment procedure, and the adjusted ratios are given in the last column with the sum of residuals.

\begin{tabular}{l|c|c}
\hline \hline & Measured mass (grams) & Lin. coef. exp. \\
\hline Ball A & 1043.352056 & 0.000012272 \\
Ball B & 1043.482802 & .000012272 \\
X2 & 200.420689 & .00000256 \\
X3 & 199.763734 & .00000256 \\
X4 & 200.010795 & .00000256 \\
X5 & 199.932675 & .00000256 \\
Sum of volumes of the 2 balls $=268.073950 \mathrm{~cm}^{3}$ at $20^{\circ} \mathrm{C}$. \\
\hline
\end{tabular}

\begin{tabular}{|c|c|c|c|c|c|}
\hline $\begin{array}{l}\text { Test } \\
\text { No. }\end{array}$ & Ratio under test & Avg test temp & $\begin{array}{l}\text { Observed ratio } \\
\text { at test temp }\end{array}$ & $\begin{array}{l}\text { Ratio reduced } \\
\text { to } 20^{\circ} \mathrm{C}\end{array}$ & L.S. adjusted ratio \\
\hline 1 & $A: B$ & 20.3187 & 1.0000028601 & 1.0000028442 & 1.0000028767 \\
\hline 2 & $\mathrm{~A}: \mathrm{X} 2+\mathrm{X} 3$ & 20.3183 & .7802953318 & .7802881037 & .7802877510 \\
\hline 3 & $\mathrm{~A}: \mathrm{X} 4+\mathrm{X} 5$ & 20.3168 & .7807629276 & .7807556860 & .7807560134 \\
\hline 4 & $\mathrm{~B}: \mathrm{X} 2+\mathrm{X} 3$ & 20.3194 & .7802923978 & .7802851145 & .7802855064 \\
\hline 5 & $\mathrm{~B}: \mathrm{X} 4+\mathrm{X} 5$ & 20.3205 & .7807614394 & .7807541343 & .7807537675 \\
\hline \multirow[t]{2}{*}{6} & $\mathrm{X} 2+\mathrm{X} 3: \mathrm{X} 4+\mathrm{X} 5$ & 20.3176 & 1.0006000685 & 1.0006000647 & 1.0006001151 \\
\hline & & & \multicolumn{2}{|c|}{ Absolute sum of residuals $=$} & .00000515217 \\
\hline 7 & $\mathrm{~A}: \mathrm{B}$ & 20.3361 & 1.0000023160 & 1.0000023107 & 1.0000014007 \\
\hline 8 & $\mathrm{~A}: \mathrm{X} 2+\mathrm{X} 4$ & 20.3370 & .7798135876 & .7798059447 & .7798063201 \\
\hline 9 & $\mathrm{~A}: \mathrm{X} 3+\mathrm{X} 5$ & 20.3370 & .7812466828 & .7812390037 & .7812393385 \\
\hline 10 & $\mathrm{~B}: \mathrm{X} 2+\mathrm{X} 4$ & 20.3359 & .7798135609 & .7798059199 & .7798052278 \\
\hline 11 & $\mathrm{~B}: \mathrm{X} 3+\mathrm{X} 5$ & 20.3346 & .7812458895 & .7812382618 & .7812382442 \\
\hline \multirow[t]{2}{*}{12} & $\mathrm{X} 2+\mathrm{X} 4: \mathrm{X} 3+\mathrm{X} 5$ & 20.3336 & 1.0018380683 & 1.0018380664 & 1.0018376594 \\
\hline & & & \multicolumn{2}{|c|}{ Absolute sum of residuals $=$} & .0000027368 \\
\hline 13 & $A: B$ & 20.3533 & 1.0000013838 & 1.0000014360 & 1.0000004250 \\
\hline 14 & $\mathrm{~A}: \mathrm{X} 2+\mathrm{X} 5$ & 20.3519 & .7799632731 & .7799553009 & .7799560148 \\
\hline 15 & $\mathrm{~A}: \mathrm{X} 3+\mathrm{X} 4$ & 20.3501 & .7810926282 & .7810846634 & .7810847381 \\
\hline 16 & $\mathrm{~B}: \mathrm{X} 2+\mathrm{X} 5$ & 20.3482 & .7799633471 & .7799554589 & .7799556833 \\
\hline 17 & $\mathrm{~B}: \mathrm{X} 3+\mathrm{X} 4$ & 20.3470 & .7810933265 & .7810854207 & .7810844062 \\
\hline \multirow[t]{2}{*}{18} & $\mathrm{X} 2+\mathrm{X} 5: \mathrm{X} 3+\mathrm{X} 4$ & 20.3474 & 1.0014459694 & 1.0014459580 & 1.0014471628 \\
\hline & & & \multicolumn{2}{|c|}{ Absolute sum of residuals $=$} & .0000042435 \\
\hline 19 & $\mathrm{X} 2: \mathrm{X} 3$ & 20.3157 & 1.0032860536 & 1.0032860446 & 1.0032863403 \\
\hline 20 & $\mathrm{X} 2: \mathrm{X} 4$ & 20.3168 & 1.0020459883 & 1.0020459770 & 1.0020468304 \\
\hline 21 & $\mathrm{X} 2: \mathrm{X} 5$ & 20.3169 & 1.0024388963 & 1.0024388959 & 1.0024377467 \\
\hline 22 & $\mathrm{X} 3: \mathrm{X} 4$ & 20.3186 & .9987632820 & .9987632796 & .9987645502 \\
\hline 23 & $\mathrm{X} 3: \mathrm{X} 5$ & 20.3163 & .9991551669 & .9991551626 & .9991541860 \\
\hline \multirow[t]{2}{*}{24} & $\mathrm{X} 4: \mathrm{X} 5$ & 20.3170 & 1.0003879913 & 1.0003879932 & 1.0003901178 \\
\hline & & & \multicolumn{2}{|c|}{ Absolute sum of residuals $=$} & .0000066700 \\
\hline
\end{tabular}


This table presents the volumetric ratios between the four silicon crystals and the two steel balls employed in Determination CD. As pointed out in the text the "ratios at test temperature" are calculated from the previously measured mass value and the weight in liquid measured hydrostatically. The ratios at $20^{\circ} \mathrm{C}$ involve assumed values of temperature coefficients of expansion. These assumed masses and coefficients are given below. These ratios at $20^{\circ} \mathrm{C}$ are submitted (in groups of six) to the Connor-Youden least square adjustment procedure, and the adjusted ratios are given in the last column with the sum of residuals.

\begin{tabular}{|c|c|c|}
\hline & Measured mass (grams) & Lin. coef. exp. \\
\hline Ball C & 1043. 941406 & $\begin{array}{llll}0.000 & 012 & 272\end{array}$ \\
\hline Ball D & 1042. 909214 & $\begin{array}{llll}.000 & 012 & 272\end{array}$ \\
\hline $\mathrm{X} 2$ & 200. 420653 & $.000 \quad 00256$ \\
\hline $\mathrm{X} 3$ & 199. $763 \quad 663$ & $.000 \quad 00256$ \\
\hline $\mathrm{X} 4$ & 200. 010763 & $.000 \quad 002 \quad 56$ \\
\hline X5 & 199. 932620 & $.000 \quad 002 \quad 56$ \\
\hline
\end{tabular}

\begin{tabular}{|c|c|c|c|c|c|}
\hline $\begin{array}{l}\text { Test } \\
\text { No. }\end{array}$ & $\begin{array}{c}\text { Ratio under } \\
\text { test }\end{array}$ & $\begin{array}{l}\text { Avg test } \\
\text { temp }\end{array}$ & $\begin{array}{l}\text { Observed ratio } \\
\text { at test temp }\end{array}$ & $\begin{array}{l}\text { Ratio reduced } \\
\text { to } 20^{\circ} \mathrm{C}\end{array}$ & $\begin{array}{l}\text { L.S. adjusted } \\
\text { ratio }\end{array}$ \\
\hline 1 & C:D & 19.1941 & 0.9999902719 & 0.9999903218 & 0.9999899545 \\
\hline 2 & $\mathrm{C}: \mathrm{X} 2+\mathrm{X} 3$ & 19.1931 & .7802638204 & .7802821681 & .7802820581 \\
\hline 3 & $\mathrm{C}: \mathrm{X} 4+\mathrm{X} 5$ & 19.1925 & .7807321977 & .7807505575 & .7807509544 \\
\hline 4 & $\mathrm{D}: \mathrm{X} 2+\mathrm{X} 3$ & 19.1933 & .7802711575 & .7802895033 & .7802898965 \\
\hline 5 & $\mathrm{D}: \mathrm{X} 4+\mathrm{X} 5$ & 19.1928 & .7807411148 & .7807594778 & .7807587975 \\
\hline \multirow[t]{2}{*}{6} & $\mathrm{X} 2+\mathrm{X} 3: \mathrm{X} 4+\mathrm{X} 5$ & 19.1913 & 1.0006005705 & 1.0006005686 & 1.0006009318 \\
\hline & & & \multicolumn{2}{|c|}{ Absolute sum of residuals $=$} & 0.0000023109 \\
\hline 7 & C:D & 19.1742 & .9999902037 & 0.9999902105 & .9999903037 \\
\hline 8 & $\mathrm{C}: \mathrm{X} 2+\mathrm{X} 4$ & 19.1748 & .7797814847 & .7798002324 & .7798001020 \\
\hline 9 & $\mathrm{C}: \mathrm{X} 3+\mathrm{X} 5$ & 19.1758 & .7812152264 & .7812340008 & .7812340586 \\
\hline 10 & $\mathrm{D}: \mathrm{X} 2+\mathrm{X} 4$ & 19.1770 & .7797887982 & .7798074949 & .7798076632 \\
\hline 11 & $\mathrm{D}: \mathrm{X} 3+\mathrm{X} 5$ & 19.1781 & .7812230169 & .7812417295 & .7812416338 \\
\hline \multirow[t]{2}{*}{12} & $\mathrm{X} 2+\mathrm{X} 4: \mathrm{X} 3+\mathrm{X} 5$ & 19.1774 & 1.0018388271 & 1.0018388285 & 1.0018388772 \\
\hline & & & \multicolumn{2}{|c|}{ Absolute sum of residuals $=$} & 0.0000005943 \\
\hline 13 & $\mathrm{C}: \mathrm{D}$ & 19.1771 & 0.9999898783 & 0.9999898601 & 9999899070 \\
\hline 14 & $\mathrm{C}: \mathrm{X} 2+\mathrm{X} 5$ & 19.1764 & .7799335893 & .7799523068 & .7799524297 \\
\hline 15 & $\mathrm{C}: \mathrm{X} 3+\mathrm{X} 4$ & 19.1763 & .7810629297 & .7810816678 & .7810815082 \\
\hline 16 & $\mathrm{D}: \mathrm{X} 2+\mathrm{X} 5$ & 19.1753 & .7799418941 & .7799606345 & .7799603018 \\
\hline 17 & $\mathrm{D}: \mathrm{X} 3+\mathrm{X} 4$ & 19.1755 & .7810702651 & .7810890220 & .7810893917 \\
\hline \multirow[t]{2}{*}{18} & $\mathrm{X} 2+\mathrm{X} 5: \mathrm{X} 3+\mathrm{X} 4$ & 19.1754 & 1.0014478970 & 1.0014478942 & 1.0014476248 \\
\hline & & & \multicolumn{2}{|c|}{ Absolute sum of residuals $=$} & 0.0000013011 \\
\hline 19 & $\mathrm{X} 2: \mathrm{X} 3$ & 19.1674 & 1.0032889403 & 1.0032889517 & 1.0032884305 \\
\hline 20 & $\mathrm{X} 2: \mathrm{X} 4$ & 19.1661 & 1.0020461432 & 1.0020461603 & 1.0020461508 \\
\hline 21 & $\mathrm{X} 2: \mathrm{X} 5$ & 19.1669 & 1.0024379242 & 1.0024379280 & 1.0024384582 \\
\hline 22 & X3:X4 & 19.1703 & 0.9987618535 & 0.9987618281 & 0.9987617920 \\
\hline 23 & $\mathrm{X} 3: \mathrm{X} 5$ & 19.1687 & .9991533078 & .9991532965 & .9991528136 \\
\hline \multirow[t]{2}{*}{24} & $\mathrm{X} 4: \mathrm{X} 5$ & 19.1701 & 1.0003915491 & 1.0003915520 & 1.0003915063 \\
\hline & & & \multicolumn{2}{|c|}{ Absolute sum of residuals $=$} & 0.0000016255 \\
\hline
\end{tabular}


This table presents the volumetric ratios between the four silicon crystals and the two steel balls employed in Determination EF. As pointed out in the text the "ratios at test temperature" are calculated from the previously measured mass value and the weight in liquid measured hydrostatically. The ratios at $20^{\circ} \mathrm{C}$ involve assumed values of temperature coefficients of expansion. These assumed masses and coefficients are given below. These ratios at $20^{\circ} \mathrm{C}$ are submitted (in groups of six) to the Connor-Youden least square adjustment procedure, and the adjusted ratios are given in the last column with the sum of residuals.

\begin{tabular}{c|c|c}
\hline \hline & Measured mass (grams) & Lin. coef. exp. \\
\cline { 2 - 3 } Ball E & 1043.351968 & 0.000012272 \\
Ball F & 1043.482847 & .000012272 \\
X2 & 200.420679 & .00000256 \\
X3 & 199.763687 & .00000256 \\
X4 & 200.010802 & .00000256 \\
X5 & 199.932659 & .00000256 \\
Sum of volumes of the 2 balls $=134.073994 \mathrm{~cm}^{3}$ at $20^{\circ} \mathrm{C}$. \\
\hline
\end{tabular}

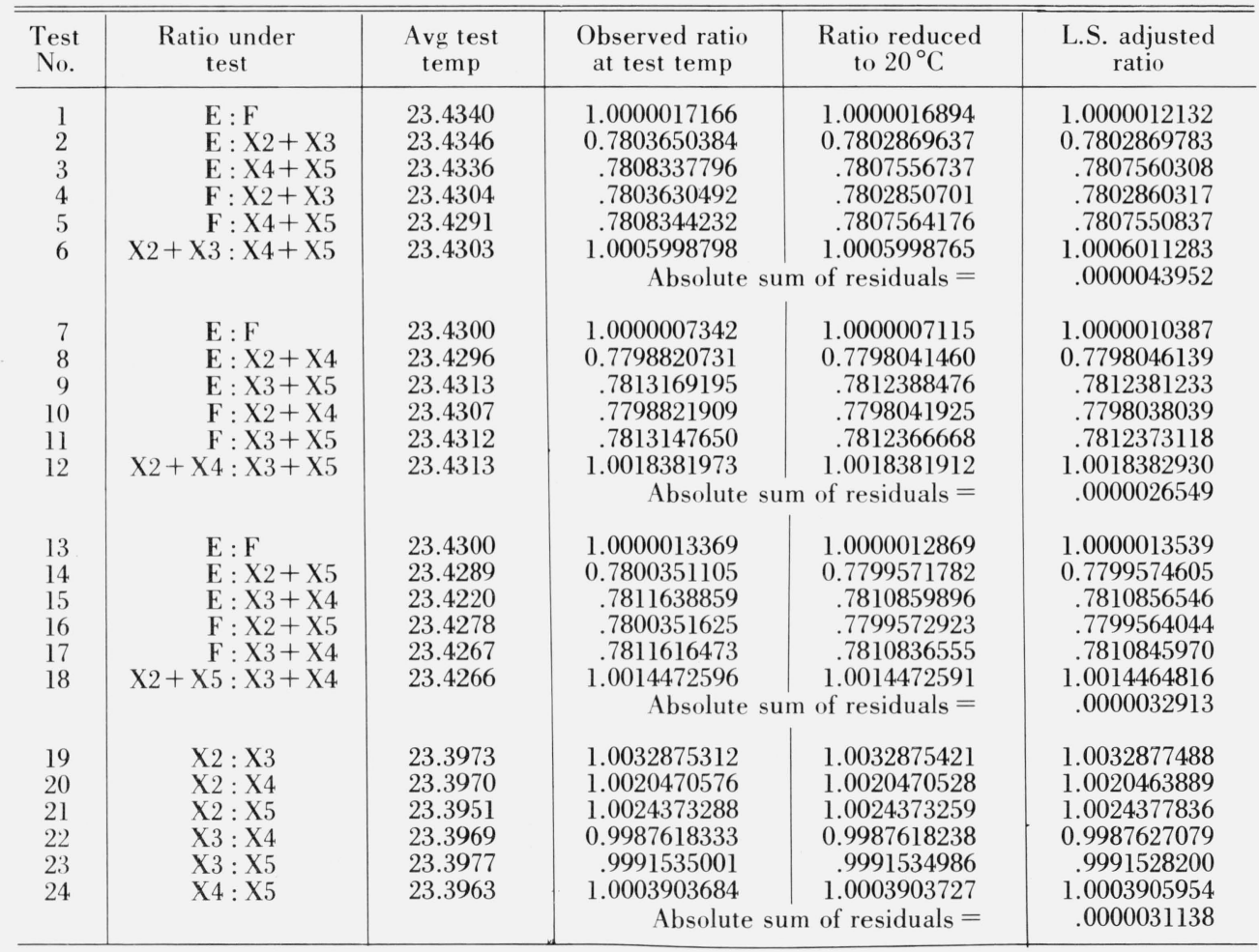

six objects (four crystals and two balls) used in the hydrostatic tests. For example, the first three equations are:

$$
\begin{aligned}
\frac{A}{B} & =1.0000028767 \\
\frac{A}{\mathrm{X} 2+\mathrm{X} 3} & =0.780287 \quad 7510 \\
\frac{A}{\mathrm{X} 4+\mathrm{X} 5} & =0.7807560134 \quad \text { etc. }
\end{aligned}
$$

These 24 equations all express relative volumetric information. To this system of equations we add a 25 th which expresses absolute volumetric informationnamely the sum of the volumes of the two steel balls used in the tests. This sum is obtained by adding the values of the two ball volumes at $20{ }^{\circ} \mathrm{C}$ given in the captions to tables 4 which are based upon direct interferometric measurement.

These 25 equations are solved for six unknowns, namely the volumes of four crystals and two balls, by the method of least squares. Two possible criticisms may be raised to the calculation of volumes by this method:

1. The data have been smoothed twice, once within the six ratios, and again in the 4 sets of ratios,

2. the observed data appear in the coefficients of the observational equations rather than as a separate term.

We have not evaluated the effect of the above, but have calculated the volumes in another way for comparison. 
Treating each set of six adjusted ratios separately with the sum of volumes of steel balls, we calculate, for example, the volumes of X2+X3 and X4+X 5 . Then the individual volumes are solved by adding two appropriate measured ratios of the crystals in the fourth set. Thus three sets of volumes are obtained for each set of ball-temperature combinations.

The differences in volumes from the two methods of computation are found to be negligible, and we decided to use values resulting from least squares fitting. The least squares estimate of the volumes of each of the four crystals and two balls are given in table 6 . This table has four columns. The first three columns show the six volumes obtained in each of the three determinations and the fourth column shows the average values which (until additional work is done) will be our presently accepted values of the crystal densities. their associated temperatures are averaged to provide one value of etalon length at some particular temperature.

b. Four measurements on the average diameter of each of two balls. Each diametric measurement is the average of ten observations as explained in 2.4.2.5. The four average diameters along with their associated temperatures are averaged to provide a single value of the average diameter at some particular temperature. The assumed etalon length employed in this step is obtained from the step a above, and appropriately adjusted by the application of our assumed value of the temperature coefficient of expansion of the etalon.

c. A group of mass measurements on each of the two balls.

TABLE 6

The results of the least squares solution for the volumes of the crystals and the balls are given in this table. Also presented are the assumed mass values of the four crystals used in each determination. At the bottom, the quotient of the assumed mass divided by the least squares estimate of volume (i.e. density) is given for each crystal and each determination. The average density value is the presently "accepted" value.

\begin{tabular}{|c|c|c|c|c|c|}
\hline & & Determination $\mathrm{AB}$ & Determination CD & Determination EF & Average value of density and \\
\hline Silicon crystal volumes $\left(\mathrm{cm}^{3}\right)$ & $\begin{array}{l}\mathrm{X} 2 \\
\mathrm{X} 3 \\
\mathrm{X} 4 \\
\mathrm{X} 5\end{array}$ & $\begin{array}{ll}86.049 & 744 \\
85.767 & 873 \\
85.874 & 004 \\
85.840 & 520\end{array}$ & $\begin{array}{ll}86.049 & 821 \\
85.767 & 793 \\
85.874 & 036 \\
85.840 & 466\end{array}$ & $\begin{array}{ll}86.049 & 800 \\
85.767 & 886 \\
85.874 & 058 \\
85.840 & 488\end{array}$ & $\begin{array}{l}\text { average. This is the accepted } \\
\text { value as explained in the } \\
\text { text. }\end{array}$ \\
\hline $\begin{array}{l}\text { Steel ball volumes }\left(\mathrm{cm}^{3}\right) \\
\text { First Ball } \\
\text { Least square estimate } \\
\text { Measured value } \\
\text { Difference } \\
\text { Second Ball } \\
\text { Least square estimate } \\
\text { Measured value } \\
\text { Difference }\end{array}$ & & $\begin{array}{c}\text { Ball A } \\
134.067080 \\
134.067062 \\
-0.000018 \\
\text { Ball B } \\
134.066870 \\
134.066888 \\
+0.000018\end{array}$ & $\begin{array}{c}\text { Ball C } \\
134.066237 \\
134.066261 \\
+0.000024 \\
\text { Ball D } \\
134.067571 \\
134.067547 \\
-0.000024\end{array}$ & $\begin{array}{c}\text { Ball E } \\
134.067078 \\
134.067028 \\
-0.000050 \\
\text { Ball F } \\
134.066916 \\
134.066966 \\
+0.000050\end{array}$ & \\
\hline Crystall mass (grams & $\begin{array}{l}\mathrm{X} 2 \\
\mathrm{X} 3 \\
\mathrm{X} 4 \\
\mathrm{X} 5\end{array}$ & $\begin{array}{ll}200.420 & 689 \\
199.763 & 734 \\
200.010 & 795 \\
199.932 & 675\end{array}$ & $\begin{array}{cc}200.420 & 653 \\
199.763 & 663 \\
200.010 & 763 \\
199.932 & 620\end{array}$ & $\begin{array}{l}200.420679 \\
199.763687 \\
200.010802 \\
199.932659\end{array}$ & \\
\hline Crystal densities $\left(\mathrm{g} / \mathrm{cm}^{3}\right)$ & $\mathrm{X} 4$ & $\begin{array}{l}2.3291259 \\
2.3291208\end{array}$ & 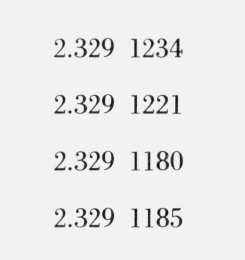 & $\begin{array}{ll}2.329 & 1243 \\
2.329 & 1199 \\
2.329 & 1179 \\
2.329 & 1184\end{array}$ & $\begin{array}{ll}2.329 & 1245 \\
0.000 & 0007 \\
2.329 & 1209 \\
0.000 & 0006 \\
2.329 & 1184 \\
0.000 & 0004 \\
2.329 & 1182 \\
0.000 & 0003\end{array}$ \\
\hline
\end{tabular}

\subsubsection{Precision and Estimate of System Errors}

A single determination on the volumes of our four silicon crystals requires the following measurements.

a. Two measurements on the length of the etalon as described in 2.4.2.4. These two lengths and d. A group of mass measurements on each of the four silicon crystals.

e. Twenty-four hydrostatic comparisons (in four 4-1 ratio series) between the volumes of the two balls and various combinations of the four crystals. 
During the winter of 1970-1 we worked on our redundant hydrostatic weighing process. To check the process precision, we performed the complete hydrostatic comparison between balls $\mathrm{A}$ and $\mathrm{B}$ and the four silicon crystals at a temperature of about $23.4{ }^{\circ} \mathrm{C}$. We were aware of the crudeness of our knowledge of the temperature coefficients of expansion involved (there is no "good" way to measure a ball's coefficient), and we had no intention of using this experiment in a real volumetric determination - we considered this only as a precision test.

In 1971-2 we performed determinations $\mathrm{A}-\mathrm{B}$ and $\mathrm{C}-\mathrm{D}$ at temperatures within one degree of $20^{\circ} \mathrm{C}$. At this time it was pointed out to us by $\mathrm{H}$. H. Ku of our Applied Mathematics Division that our experiments over this very limited temperature range were highly nonrealistic, and that we should make every effort to achieve a determination at a temperature at least $2^{1} / \mathbf{2}^{\circ} \mathrm{C}$ away from 20.

Our interferometer was designed to operate at a maximum temperature of $22{ }^{\circ} \mathrm{C}$, however we found that, at the sacrifice of some thermostat stability, we could operate marginally at a temperature of $23{ }^{\circ} \mathrm{C}$. Accordingly, we made etalon tests ET-5 and ET-6 at $23{ }^{\circ} \mathrm{C}$ and also measured the diameters of balls $\mathrm{A}$ and $\mathrm{B}$ at this temperature. Additional mass measurements were made. These new data at $23{ }^{\circ} \mathrm{C}$ were combined with the early hydrostatic work at $23.4{ }^{\circ} \mathrm{C}$ and new crystal volumes were calculated. Although balls A and $B$ were employed, in this high temperature determination we have referred to them as balls $\mathrm{E}$ and $F$. Inasmuch as this work on $E$ and $F$ contains all the elements of a single determination as defined above, we feel justified in claiming three independent determinations.

Our presently "accepted" values of the crystal densities are the average of the three determinations. As stated above, as additional work is done on these four crystals our accepted values will be modified. The standard deviations of these average values of crystal volume are given in table 6 . These standard deviations are indicative of the reproducibility of our system in the determination of such volumes.

As pointed out in the previous section, the data presented in table 6 are obtained from a least-squares solution of 25 equations -24 relating the relative volumes of crystals and balls and the 25th stating our best estimate of the sum of the volumes of the two balls. Out of the least squares solution we obtain an estimate of the volumes of each of the four crystals as well as an estimate of the volumes of each of the two balls. A comparison between the least square estimates of the individual ball volumes and our measured values (used in calculating the sum) is indicative of the inconsistency between our interferometric tests and our hydrostatic tests. These differences are shown in table 6 .

An examination of the three sets of density values did not reveal any discernible pattern in rank. Statistical analysis of the volume and density data for three sets also supported the contention that a between-set component of error, if any, was negligible. The measured masses of the four silicon crystals, on the other hand, did show that the A-B set was on the average $50 \mu \mathrm{g}, 0.25 \mathrm{ppm}$, higher than the C-D set, but the effect of this discrepancy on densities was not obvious. A possible explanation could be that these values of masses were used first in the computation of volume ratios and then in the computation of densities. The correlation between the numerator and denominator of the density computation would tend to decrease the effect of any systematic error present in the mass on the density values. Since these measured mass values were assigned to the sets of volume ratio calculations by date, an alternate way of computation could be to use the averages of the three sets of mass values in all density calculations. We will, however, adhere to the present scheme of calculation so that the random component of error can be computed from the three sets of final results as planned.

The standard deviation of density values of each determination was computed to be $0.97 \mu \mathrm{g} / \mathrm{cm}^{3}$ with 8 degrees of freedom. The random component of uncertainty of the averages of density values of three determinations is taken as three standard deviations of these averages, $1.68 \mu \mathrm{g} / \mathrm{cm}^{3}$, or $0.72 \mathrm{ppm}$.

To the extent that the same array of apparatus and instruments is used in all three determinations, the three determinations are not entirely independent. There are residual uncertainties in the calibrations of such instruments, and when these calibration uncertainties exert the same effect on the crystal densities calculated in each determination, they do not increase the data spread shown in table 6 , so they are not included in the standard deviation of the mean given in that table.

The major sources of such uncertainties going into each determination are listed in table 7. Alongside of each item of source data (which may be an instrument such as a thermocouple or a process such as a weighing experiment to determine mass) is our estimated bound to the systematic uncertainty in that item.

Also shown is the effect of the error on the calculated crystal density obtained in each of the three determinations. It is noted that the effects of such errors on calculated densities classify the errors into two groups:

a. When the effect of the error on the volumetric calculation is the same in each of the three determinations. This group of errors must be assigned to the systematic category.

b. When the effect of the error on the volumetric calculation is different in each of three determinations. This group consists of errors, the effects of which are temperature dependent. Inasmuch as the temperature pattern in the various tests was grossly different, this group of errors need not be classed as systematic because their effect is present in the spread of data shown in figure 6 .

We have no basis for assigning a value of uncertainty to the $22^{\circ}$ phase shift used in interferometer calcula- 


\begin{tabular}{|c|c|c|c|c|}
\hline \multirow{2}{*}{ Source data } & \multirow{2}{*}{$\begin{array}{l}\text { Estimated } \\
\text { magnitude } \\
\text { of error in } \\
\text { source data }\end{array}$} & \multicolumn{3}{|c|}{$\begin{array}{l}\text { Effect of estimated error on calculated values of } \\
\text { crystal densities }\left(\mathrm{g} / \mathrm{cm}^{3}\right)\end{array}$} \\
\hline & & Determination AB & Determination CD & Determination EF \\
\hline \multicolumn{5}{|l|}{$\begin{array}{l}\text { Data items in which errors exert the same effect } \\
\text { in all three determinations and are therefore } \\
\text { systematic }\end{array}$} \\
\hline 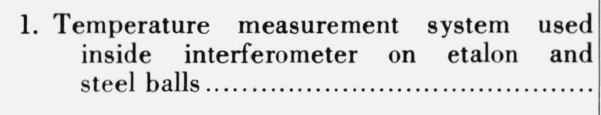 & $0.0092^{\circ} \mathrm{C}$ & $7.89 \times 10^{-7}$ & & \\
\hline $\begin{array}{l}\text { 2. Calibration errors in system used to cal- } \\
\text { culate effective wavelength of inter- } \\
\text { ferometer illumination.................................... }\end{array}$ & $2.5 \times 10^{-8} \mu$ & $2.67 \times 10^{-7}$ & & \\
\hline $\begin{array}{l}\text { 3. Fringe fraction calculated from photo- } \\
\text { graphic system }\end{array}$ & \multirow{2}{*}{$\begin{array}{l}0.001 \\
0.0015^{\circ} \mathrm{C}\end{array}$} & $0.18 \times 10^{-7}$ & & \\
\hline 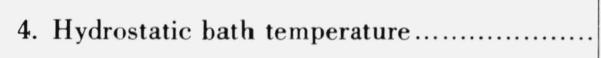 & & \multirow{4}{*}{$\begin{array}{l}1.02 \times 10^{-7} \\
6.25 \times 10^{-7} \\
1.62 \times 10^{-7} \\
9.28 \times 10^{-7}\end{array}$} & & \\
\hline 5. Mass of one steel ball ....... & \multirow{2}{*}{$\begin{array}{l}0.000064 \mathrm{~g} \\
0.000090 \mathrm{~g}\end{array}$} & & & \\
\hline 6. Mass of two silicon crystals........................ & & & & \\
\hline 7. Calibration errors in hydrostatic balance ..... & $13 \mu \mathrm{g} / 100 \mathrm{~g}$ & & & \\
\hline $\begin{array}{l}\text { Absolute sum of systematic errors (worst case)..... } \\
\text { Realsitic estimate (square root of sum of squares). }\end{array}$ & . & \multicolumn{2}{|c|}{$\begin{array}{l}28.91 \times 10-7=1.25 \quad \mathrm{ppm} \\
14.10 \times 10-7=0.60 \quad \mathrm{ppm}\end{array}$} & \\
\hline \multicolumn{5}{|l|}{$\begin{array}{l}\text { Data items which are temperature dependent } \\
\text { and therefore contribute to random component }\end{array}$} \\
\hline 8. Expansion coefficient of etalon........................ & \multirow{2}{*}{$\begin{array}{l}3 \times 10^{-8} \\
5 \times 10^{-8}\end{array}$} & $-0.63 \times 10^{-7}$ & $+0.33 \times 10^{-7}$ & $+0.10 \times 10^{-7}$ \\
\hline 9. Expansion coefficient of balls . & & $-1.40 \times 10^{-7}$ & $+3.75 \times 10^{-7}$ & $-1.72 \times 10^{-7}$ \\
\hline 10. Expansion coefficient of crystals . & $9 \times 10^{-8}$ & $+0.67 \times 10^{-7}$ & $-1.69 \times 10^{-7}$ & $+7.20 \times 10^{-7}$ \\
\hline
\end{tabular}

\section{MEASURED DENSITY}

OF SILICON CRYSTALS AT $20^{\circ} \mathrm{C}$

(gram $/ \mathrm{cm}^{3}$ )

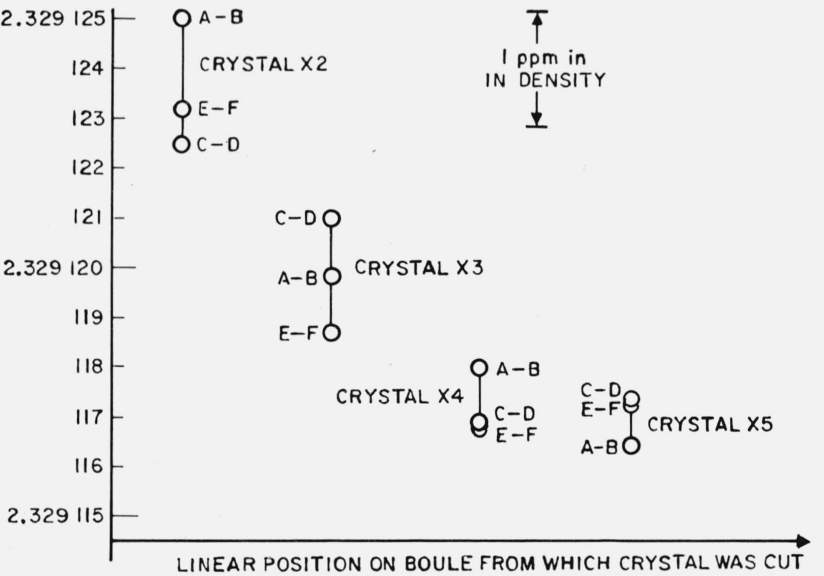

Figure 6. This figure illustrates the spread of density data for each crystal among its three determinations.

We have made several previous attempts to measure the density gradient in single crystal silicon boules. This graph is the best display of the existence of such a gradient which has come to our attention. We deeply regret that a particularly well-remembered which has come to our attention. We deeply regret that a particularly well-remembered
day in history marked the beginning of our utilization of Crystal Xl for the fabrication of day in history marked the begign
fractional-gram silicon weights. tions. Additionally our estimate of item 9 may be weak. The square root of the sum of the squares of items 1 to 7 indicates a systematic of $0.6 \mathrm{ppm}$. We believe that $0.7 \mathrm{ppm}$ is a justified and conservative estimate of the total systematics in this work.

The density program described in this report has involved numerous scientists in various divisions of NBS. The following individuals have given generously of their time and talents. D. P. Johnson has been our primary theoretical consultant. He worked out the data taking and reduction procedures for the interferometric part of the experiment on the etalon and balls. He calculated the volumetric uncertainty associated with ball imperfections (given in a companion paper). R. D. Deslattes provided us with adequate values of laser wavelengths and suggested the use of single crystal silicon as a working density standard. J. B. Saunders developed the spherical interferometer at our request. W. H. Gallagher assisted in working out adequate hydrostatic procedures. $\mathrm{H}$. $\mathrm{H}$. $\mathrm{Ku}$ played a major role in experiment design and he worked out 
the hydrostatic data reduction format. J. L. Riddle gave us guidance in building and evaluating our interferometer temperature measurement system. Geraldine Hailes wrote many computer programs for us especially in the early stages of development when numerical techniques were only hazy ideas.

\section{References}

[1] Cook, A. H., and Stone, N. W. B.. Precise Measurements of Mercury at $20^{\circ} \mathrm{C}-\mathrm{I}$, Phil. Trans. Roy Soc. 250A (1957).

[2] Cook, A. H., Precise Measurements of the Density of Mercury at $20^{\circ} \mathrm{C}$-II, Phil. Trans. Roy. Soc. 254 (1961-2).

[3] Henins and Bearden, Phys. Rev. 135, A890 (1964).

[4] Deslattes, R. D., and Sauder, W. C., Intercomparison of Micrometer, Nanometer and Picometer Wavelengths, Proc. 4th Int'l. Conf. on Atomic Masses and Fundamental Constants, Teddington (1971).

[5] Bowman, H. A.. Gallagher, W. H., and Schoonover, R. M.. Development of a Working Density Standard, Proc. ISA, Los Angeles (1965).

[6] Bowman, H. A., and Schoonover, R. M., The Cartesian Diver as a Density Comparator, J. Res. Nat. Bur. Stand. (U.S.), 69C (Eng. and Instr.), No. 3, 217-223 (1965).

[7] Deslattes, R. D., Schweitzer, W. G., Layer, H. P., Sidener, C., Whetstone, J. M., and Kessler, E. G., Wavelengths of $633 \mathrm{~nm}$ Stabilized Lasers (in process).
[8] Saunders, J. B., Ball and Cylinder Interferometer, J. Res. Nat. Bur. Stand. (U.S.), 76C (Eng. and Instr.), Nos. 1 and 2 (1972).

[9] Teague, Clayton, NBS Private Communication.

[10] Hart, M, and Morgan, I. G., Lattice Spacing Measurements and Avagadro's Number, Proc. 4th Int'l Conf. on Atomic Masses and Fundamental Constants, Teddington (1971).

[11] Everhart, J. L., Lindlief, W. E., Kanegis, J., Weissler, P. G., and Siegel, F., Mechanical Properties of Metals and Alloys, Nat. Bur. Stand. (U.S.), Circ. 447, 481 pages (1943).

[12] Bennett, J. M., Precise Method for Measuring the Absolute Phase Change on Reflection, Jour. Opt. Soc. Amer. 54, No. 5 , p. 612 (May 1961).

[13] Spaepen, J., Application of the Float Method for Precision Measurement of the Density of Water and for Small Samples of Solids, Mededel. Koninkl. Vlaam. Akad. Wetenschap. Belg. 19, No. 5 (1957).

[14] Bowman, H. A., and Schoonover, R. M., with appendix by Jones, M. W., Procedure for High Precision Density Determinations by Hydrostatic Weighing, J. Res. Nat. Bur. Stand. (U.S.), 71 C (Eng. and Instr.), No. 3, 179-198 (1967).

[15] Macurdy, L. B., Response of Highly Precise Balances to Thermal Gradients, J. Res. Nat. Bur. Stand. (U.S.), 68C (Eng. and Instr.), No. 3, 135-140 (1964).

[16] Pontius, P. E.. Measurement Philosophy of the Pilot Program for Mass Calibration, Nat. Bur. Stand. (U.S.), Tech. Note 288, 39 pages (May 1966).

[17] Connor, W. S., and Youden, W. J., Part II Comparison of Four National Radium Standards, J. Res. Nat. Bur. Stand. (U.S. 53) (Engr. and Instr.), No. 5, 108 (1954).

(Paper 78Al-801) 